\title{
Four new genera and five new species of 'Heterocypris' from Western Australia (Crustacea, Ostracoda, Cyprinotinae)
}

\author{
Stuart A. HALSE ${ }^{1} \&$ Koen MARTENS ${ }^{2, *}$ \\ ${ }^{1}$ Bennelongia Environmental Consultants, 5 Bishop Street, Jolimont WA 6014, Australia. \\ ${ }^{2}$ Royal Belgian Institute of Natural Sciences, OD Nature, Freshwater Biology, \\ Vautierstraat 29, B-1000 Brussels, Belgium. \\ ${ }^{2}$ University of Ghent, Department of Biology, K.L. Ledeganckstraat 35, B-9000 Gent, Belgium. \\ *Corresponding author: darwinula@gmail.com \\ ${ }^{1}$ Email: stuart.halse@bennelongia.com.au \\ ${ }^{1}$ urn:1sid:zoobank.org:author:676014BF-5979-49EC-BC8F-811214170111 \\ ${ }^{2}$ urn:1sid:zoobank.org:author:9272757B-A9E5-4C94-B28D-F5EFF32AADC7
}

\begin{abstract}
Five new species in four new genera from Western Australia are described. All species have valve characters that are reminiscent of the genus Heterocypris Claus, 1892 and also have similar valve outlines, with highly arched valves. However, all species have a hemipenis morphology that is totally different from the typical form in Heterocypris. In Patcypris gen. nov. (with type species P. outback gen. et sp. nov.), the lateral lobe is large and shaped as a pickaxe, while the medial lobe is divided into two distal lobes. Trilocypris gen. nov. (with type species T. horwitzi gen. et sp. nov.) is characterised by a hemipenis that has three, instead of two, distal lobes. In Bilocypris gen. nov. (with type species $B$. fortescuensis gen. et sp. nov. and a second species, B. mandoraensis gen. et sp. nov.), the lateral lobe of the hemipenis is spatulate, rather than boot-shaped, and the medial lobe is bilobed. Billcypris gen. nov. (with type species B. davisae gen. et sp. nov.) has a large and sub-rectangular lateral lobe and a pointed medial lobe. We discuss the taxonomic value of the traditional and new morphological characters and speculate that the diversity of this cluster of genera and species may be greater than currently known.
\end{abstract}

Keywords. Taxonomy, evolution, Ostracoda, aquatic biodiversity, Western Australia.

Halse S.A. \& Martens K. 2019. Four new genera and five new species of 'Heterocypris' from Western Australia (Crustacea, Ostracoda, Cyprinotinae). European Journal of Taxonomy 493: 1-35.

https://doi.org/10.5852/ejt.2019.493

\section{Introduction}

Ostracods are mostly small (ca $1 \mathrm{~mm}$ ) crustaceans with a body that is mostly fully enveloped by two calcified valves. They are abundant in most aquatic habitats, both marine and non-marine. There are presently 2331 subjective species of non-marine ostracods in 270 genera (Meisch et al. 2019). However, countless ostracod species remain to be described, and Australian aquatic inland habitats are among the notable hotspots for such undocumented diversity (Halse 2002; Halse \& McRae 2004; Martens et al. 
2008). A case in point is the recent revision of the genus Bennelongia De Deckker \& McKenzie, 1981 in Western Australia; before the revision two described species of Bennelongia were known from this state, but a further 22 species have been described, with several species awaiting description and still others probably awaiting discovery (Martens et al. 2012, 2013, 2015; Shearn et al. 2012).

There are 13 extant families among non-marine ostracods, but half of the known specific (ca 1000 species) and generic (ca 100 genera) diversity belongs to a single family, the Cyprididae. This family itself comprises 23 subfamilies +1 uncertain subfamily (Meisch et al. 2019), one of which is the cosmopolitan subfamily Cyprinotinae Bronstein, 1947. Five genera are known from this subfamily: the type genus Cyprinotus Brady, 1886 (circumtropical), Hemicypris Sars, 1903 (circumtropical), Heterocypris Claus, 1892 (cosmopolitan), Homocypris Sars, 1924 (South Africa) and Riocypris Klie, 1935 (Uruguay, South America). Whereas the first three genera share clear morphological features (one larger valve overlapping a smaller one, the latter set with marginal tubercles), the other two genera lack these marginal tubercles and are assigned to the Cyprinotinae largely on the basis of overall valve and soft part similarities. The morphology of Manuelcypris Yoo et al., 2016 and its synonymy with Heterocypris is discussed in Martens \& Higuti (in press) and Meisch et al. (2019).

The subfamily Cyprinotinae currently comprises ca 130 species worldwide, mostly in the Afrotropical region (Martens et al. 2008). The genera Cyprinotus, Hemicypris and Heterocypris are known from Australia. In addition, Karanovic (2008) refers two Western Australian species to the genus Riocypris. However, we consider that from a zoogeographical point of view this allocation is unlikely and the taxonomic placement of these species is thus uncertain. Eight species of Heterocypris have been described from Australia (Meisch et al. 2019) and several other undescribed species have already been collected in Western Australia and will be described elsewhere.

Here, we describe four new genera and five new species of Cyprinotinae from Western Australia. These new genera and species are similar to Heterocypris in valve outline and partly in valve structure. However, all five species have a hemipenis with a structure which is profoundly different from that of typical species of Heterocypris. Trilocypris gen. nov., for example, is characterised by the presence of a third lobe on the hemipenis. Patcypris gen. nov., in addition, also shows structural differences in the valves, as it lacks anterior selvages and inner lists on both valves.

\section{Material and methods}

Material used for the present paper was obtained from a variety of sources (see details for each collection and locality below in the species descriptions and in Table 1). Ostracods were collected with a hand net (mesh size $160 \mu \mathrm{m}$ ) from shallow pans or were raised from dried mud.

The type material of the five new species is deposited in two different locations, namely in the Western Australian Museum, Perth, Australia (WAM) and, with the permission of WAM, in the Invertebrate Collection of the Royal Belgian Institute of Natural Sciences (RBINS), Brussels, Belgium (RBINS INV numbers).

\section{Morphological analyses}

Ostracods were dissected, with valves stored dry in micro-palaeontological slides and soft parts in glycerine on sealed slides. Drawings of soft parts were made with a camera lucida attached to a compound microscope (Leica, DM 2500 at Bennelongia Environmental Consultants, Perth). Valves were illustrated and measured using scanning electron microscopy (Philips XL30 SEM at RBINS, Brussels). 
HALSE S.A. \& MARTENS K., New genera and species of "Heterocypris" from Western Australia

Table 1. Illustrated specimens used for the present study: museum numbers, type of specimen, gender and measurements (the latter in $\mu \mathrm{m}$, all measured by SEM, when available).

\begin{tabular}{|c|c|c|c|c|c|c|c|c|c|c|c|c|}
\hline \multirow{2}{*}{ Genus } & \multirow{2}{*}{ species } & \multirow{2}{*}{ WAM / INV } & \multirow{2}{*}{ Type } & \multirow{2}{*}{ J19 } & \multicolumn{2}{|c|}{ RV } & \multicolumn{2}{|c|}{$\mathbf{L V}$} & \multicolumn{2}{|c|}{ CPRI } & \multicolumn{2}{|c|}{$\mathrm{CpD} / \mathrm{V}$} \\
\hline & & & & & $\mathbf{L}$ & $\mathbf{H}$ & $\mathbf{L}$ & $\mathbf{H}$ & $\mathbf{L}$ & $\mathbf{H}$ & $\mathbf{L}$ & $\mathbf{W}$ \\
\hline Patcypris & outback & 67184 & Holotype & $\sigma^{\pi}$ & 1405 & 824 & 1442 & 859 & - & - & - & - \\
\hline Patcypris & outback & 67185 & Allotype & q & 1392 & 853 & 1442 & 865 & - & - & - & - \\
\hline Patcypris & outback & INV138033 & Paratype & q & 1285 & 762 & 1313 & 785 & - & - & - & - \\
\hline Patcypris & outback & 67186 & Paratype & q & - & - & - & - & 1490 & 827 & - & - \\
\hline Patcypris & outback & 67187 & Paratype & q & - & - & - & - & - & - & 1465 & 742 \\
\hline Patcypris & outback & 67188 & Paratype & $\hat{0}$ & - & - & - & - & 1218 & 732 & - & - \\
\hline Patcypris & outback & 67189 & Paratype & $\hat{\sigma}$ & - & - & - & - & - & - & 1308 & 662 \\
\hline Patcypris & outback & 67190 & Paratype & 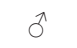 & - & - & - & - & - & - & - & - \\
\hline Patcypris & outback & INV138034 & Paratype & $\hat{0}$ & 1320 & 785 & 1364 & 796 & - & - & - & - \\
\hline Patcypris & outback & 67192 & voucher & $\hat{\sigma}$ & - & - & - & - & - & - & - & - \\
\hline Patcypris & outback & 67193 & voucher & q & 1608 & 1040 & 1644 & 1042 & - & - & - & - \\
\hline Patcypris & outback & 67195 & voucher & $\hat{\sigma}$ & 1156 & 679 & 1189 & 671 & - & - & - & - \\
\hline Patcypris & outback & 67196 & voucher & $\hat{0}$ & - & - & - & - & - & - & - & - \\
\hline Patcypris & outback & 67197 & voucher & $\hat{\sigma}$ & 1395 & 815 & 1408 & 837 & - & - & - & - \\
\hline Patcypris & outback & 67198 & voucher & $q$ & 1507 & 915 & \multicolumn{2}{|c|}{ lost } & - & - & - & - \\
\hline Trilocypris & horwitzi & 67199 & Holotype & $\hat{0}$ & 1158 & 680 & 1212 & 692 & - & - & - & - \\
\hline Trilocypris & horwitzi & 67200 & Allotype & q & \multicolumn{2}{|c|}{ lost } & 1547 & 907 & - & - & - & - \\
\hline Trilocypris & horwitzi & 67201 & Paratype & $\hat{\sigma}$ & - & - & - & - & - & - & - & - \\
\hline Trilocypris & horwitzi & INV138035 & Paratype & q & - & - & - & - & - & - & - & - \\
\hline Trilocypris & horwitzi & 67202 & Paratype & $q$ & - & - & - & - & - & - & - & - \\
\hline Trilocypris & horwitzi & 67203 & Paratype & $q$ & - & - & - & - & - & - & - & - \\
\hline Bilocypris & fortescuensis & 67205 & Holotype & $\hat{\sigma}$ & 1094 & 669 & 1147 & 673 & - & - & - & - \\
\hline Bilocypris & fortescuensis & 67206 & Allotype & q & 1191 & 720 & 1253 & 734 & - & - & - & - \\
\hline Bilocypris & fortescuensis & 67207 & Paratype & $\hat{\sigma}$ & \multicolumn{2}{|c|}{ lost } & 1147 & 689 & - & - & - & - \\
\hline Bilocypris & fortescuensis & 67208 & Paratype & $\hat{\sigma}$ & - & - & - & - & - & - & 1119 & 672 \\
\hline Bilocypris & fortescuensis & 67209 & Paratype & q & - & - & - & - & 1266 & 719 & - & - \\
\hline Bilocypris & fortescuensis & 67210 & Paratype & $q$ & - & - & - & - & - & - & - & - \\
\hline Bilocypris & fortescuensis & INV138036 & Paratype & $\hat{\sigma}$ & 1191 & 736 & 1272 & 758 & - & - & - & - \\
\hline Bilocypris & fortescuensis & 67212 & Paratype & $\hat{0}$ & - & - & - & - & 1180 & 673 & - & - \\
\hline Bilocypris & fortescuensis & 67213 & Paratype & $\hat{\sigma}$ & - & - & - & - & - & - & 1267 & 672 \\
\hline Bilocypris & fortescuensis & 67214 & Paratype & q & 1145 & 700 & 1200 & 716 & - & - & - & - \\
\hline Bilocypris & fortescuensis & 67215 & Paratype & q & - & - & - & - & 1225 & 703 & - & - \\
\hline Bilocypris & fortescuensis & 67216 & Paratype & q & - & - & - & - & - & - & 1223 & 694 \\
\hline Bilocypris & fortescuensis & INV138037 & Paratype & q & - & - & - & - & - & - & 1291 & 667 \\
\hline Billcypris & davisae & 67217 & Holotype & $\hat{\sigma}$ & 1255 & 752 & 1320 & 768 & - & - & - & - \\
\hline Billcypris & davisae & 67218 & Allotype & $q$ & 1433 & 900 & 1495 & 923 & - & - & - & - \\
\hline Billcypris & davisae & INV138038 & Paratype & $\hat{\sigma}$ & 1305 & 795 & 1368 & 812 & - & - & - & - \\
\hline Billcypris & davisae & 67219 & Paratype & q & - & - & - & - & 1458 & 931 & - & - \\
\hline Billcypris & davisae & 67220 & Paratype & q & - & - & - & - & - & - & 1410 & 802 \\
\hline Billcypris & davisae & 67221 & Paratype & $\hat{\sigma}$ & - & - & - & - & 1377 & 830 & - & - \\
\hline Billcypris & davisae & 67222 & Paratype & $\hat{\sigma}$ & - & - & - & - & - & - & 1362 & 833 \\
\hline Billcypris & davisae & 67224 & voucher & $\hat{\sigma}$ & - & - & - & - & - & - & - & - \\
\hline Bilocypris & mandoraensis & 67226 & Holotype & $\hat{\sigma}$ & 1314 & 773 & 1369 & 786 & - & - & - & - \\
\hline Bilocypris & mandoraensis & 67227 & - & - & - & - & - & - & - & - & - & - \\
\hline Bilocypris & mandoraensis & 67601 & Allotype & q & 1381 & 824 & 1447 & 823 & - & - & - & - \\
\hline Bilocypris & mandoraensis & 67602 & - & - & - & - & - & - & - & - & - & - \\
\hline Bilocypris & mandoraensis & 67603 & Paratype & q & - & - & - & - & - & - & 1428 & 761 \\
\hline Bilocypris & mandoraensis & 67604 & Paratype & q & - & - & - & - & - & - & 1491 & 808 \\
\hline Bilocypris & mandoraensis & 67605 & - & - & - & - & - & - & - & - & - & - \\
\hline
\end{tabular}


Abbreviations used in text and figures

Valves and carapaces:

$\mathrm{Cp}=$ carapace

$\mathrm{CpD}=$ carapace in dorsal view

$\mathrm{CpRL}=$ carapace in right lateral view

$\mathrm{CpV}=$ carapace in ventral view

$\mathrm{H}=$ height of valves

$\mathrm{L}=$ length of valves

$\mathrm{LVi}=$ left valve in internal view

$\mathrm{RVi}=$ right valve in internal view

$\mathrm{W}=$ width of valves

\section{Limbs:}

$\mathrm{A} 1=$ antennula

$\mathrm{A} 2=$ antenna

$\mathrm{Bc}=$ bursa copulatrix in hemipenis

$\mathrm{CR}=$ caudal ramus

$\mathrm{Hp}=$ hemipenis

Lpp $=$ left prehensile palp

ls $=$ lateral shield of hemipenis

$\mathrm{Md}=$ mandibula

$\mathrm{ms}=$ medial shield of hemipenis

$\mathrm{Mx} 1=$ maxillula

os $=$ outer shield of hemipenis

$\mathrm{Rpp}=$ right prehensile palp

$\mathrm{T} 1=$ first thoracopod

$\mathrm{T} 2=$ second thoracopod

$\mathrm{T} 3=$ third thoracopod

\section{Results}

Class Ostracoda Latreille, 1802

Subclass Podocopa G.O. Sars, 1866

Order Podocopida G.O. Sars, 1866

Suborder Cypridocopina G.O. Sars, 1866

Superfamily Cypridoidea Baird, 1845

Family Cyprididae Baird, 1845

Subfamily Cyprinotinae Bronstein, 1947

Patcypris gen. nov.

urn:lsid:zoobank.org:act:4D0801AE-7642-403E-825C-E6BE436F1F2A

\section{Type species}

Patcypris outback gen. et sp. nov. (here designated).

\section{Other species}

The genus is thus far monospecific.

\section{Diagnosis}

Valves highly arched, with LV overlapping RV on all sides. RV with or without marginal tubercles. RV and LV without anterior selvages or inner lists. A1 with segments 3-7 short and broad. Hemipenes large, with two large distal lobes, ls ventrally pointed, ms bilobed. 


\section{Etymology}

This new genus is named after Patrick 'Pat' De Deckker (Australian National University, Canberra, Australia) in recognition of his outstanding contributions to Australian limnology, palaeolimnology and the knowledge of Australian ostracods. Patrick was also a supervisor of the MSc of KM.

\section{Differential diagnosis}

Patcypris gen. nov. can be distinguished from all genera in the Cyprinotinae, including the three other new genera described below, by the complete absence of anterior selvages or inner lists in both valves. It also has a hemipenis structure different from all other genera and species in the subfamily Cyprinotinae. The new genus can furthermore be distinguished from Cyprinotus by the absence of the dorsal hump on the right valve, from Hemicypris and Homocypris by the fact that the LV overlaps the RV (inverse in Hemicypris; valves symmetrical in Homocypris) and from Riocypris by the absence of seta d2 on T2.

\section{Distribution}

The genus is currently known from inland areas across much of the latitudinal range of Western Australia (Fig. 1).

\section{Remarks}

As usual in monospecific genera, it is difficult to determine which characters will be valid at the generic level and which at the specific level. It is thus possible that the diagnosis of this new genus will have to be adapted if more congeneric species are found.

Patcypris outback gen. et sp. nov. urn:1sid:zoobank.org:act:70D7E744-8549-4F7E-BA49-05205690D315

Figs $2-5,7 \mathrm{~A}-\mathrm{B}$

\section{Diagnosis}

Valves high posteriorly, strongly arched, LV overlapping RV on all sides, RV without marginal tubercles or with marginal tubercles very small and weakly developed. RV and LV anteriorly without selvage or inner lists. A1 with segments 3-7 short and broad. Rpp with second segment large and subtriangular, with an additional proximo-dorsal lapel-like process. Lpp with second segment lacking long distal flagellum. Lobe ls of hemipenis large and shaped like a pickaxe; lobe ms divided in two distal lobes. CR in both male and female proximally strongly curved and swollen.

\section{Etymology}

This species is named after the company Outback Ecology (now part of Stantec) that collected the type material of this new species. It also refers to the Australian word 'outback' that designates any remote arid inland area on the continent. Outback Ecology worked extensively in saline playas of the outback, especially in the Goldfields region of Western Australia.

\section{Type locality}

Lake Maitland, Western Australia. Approximate coordinates: $27^{\circ} 10^{\prime} 48^{\prime \prime}$ S, $121^{\circ} 05^{\prime} 00^{\prime \prime}$ E. Dried mud collected by F. Taukulis and V. Campagna, 22 May 2007; specimens raised from dried mud and harvested from the rearing tanks on 14 Aug. 2009 (sample no. LN5217).

\section{Material examined}

\section{Holotype}

AUSTRALIA - $\mathrm{O}^{\top}$; Western Australia, Lake Maitland; $27^{\circ} 10^{\prime} 48^{\prime \prime} \mathrm{S}, 121^{\circ} 05^{\prime} 00^{\prime \prime}$ E [approximate coordinates]; 22 May 2007; F. Taukulis and V. Campagna leg.; dried mud; specimen raised from dried 


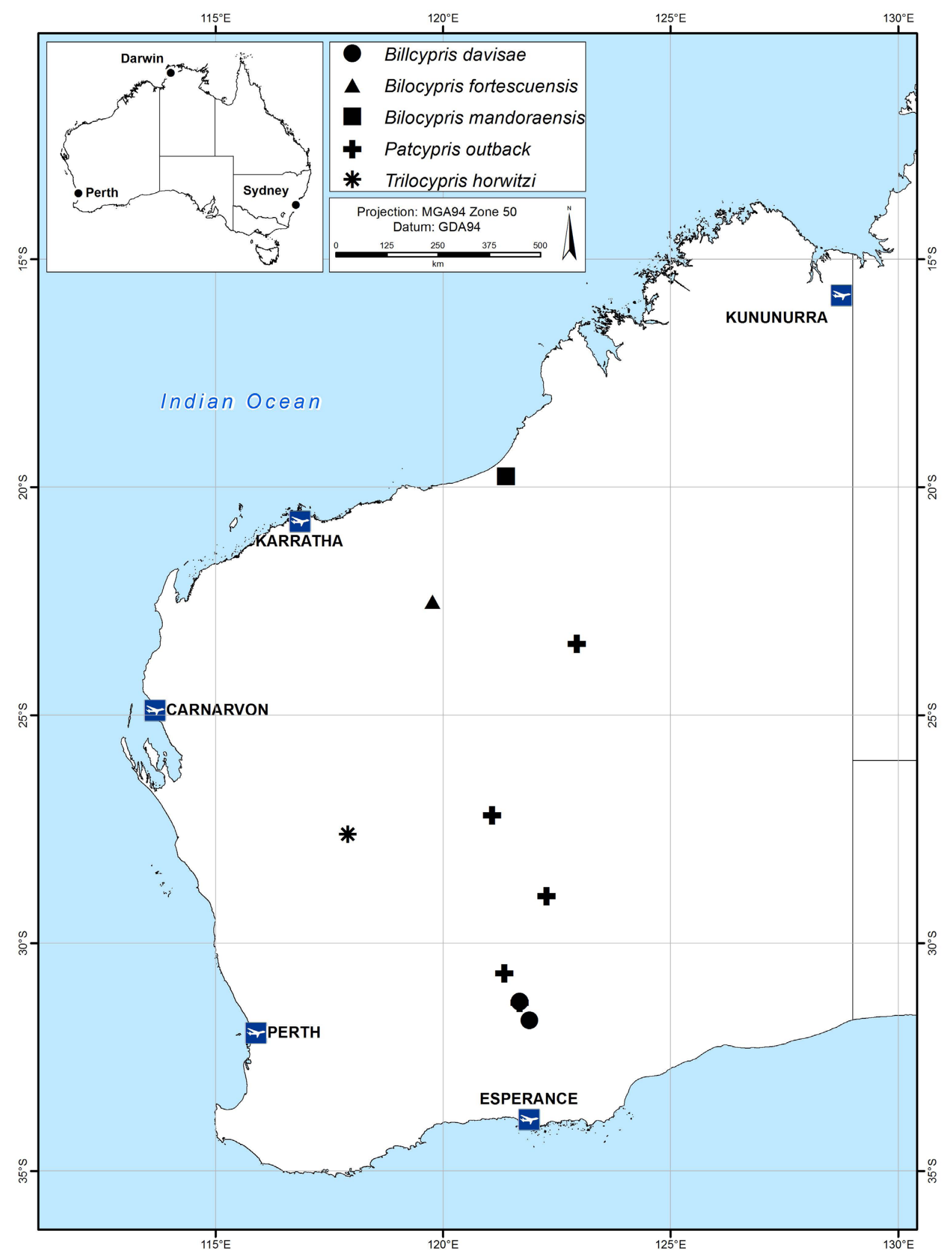

Fig. 1. Map of Western Australia, showing localities where the new species were collected. 
HALSE S.A. \& MARTENS K., New genera and species of "Heterocypris" from Western Australia

mud and harvested from the rearing tanks on 14 Aug. 2009 (sample no. LN5217); with soft parts dissected in glycerine on a sealed slide and with valves stored dry in a micropalaeontological slide; WAM 67184.

\section{Allotype}

AUSTRALIA • 9 ; same collection data as for holotype; with valves stored dry in a micropalaeontological slide and soft parts used for (failed) molecular analyses; WAM 67185.

\section{Paratypes}

AUSTRALIA - Several $q Q+$ and $\widehat{\partial} \delta^{\lambda}$; same collection data as for holotype; either dissected and stored in the same way as the holotype, or as carapaces used for SEM; WAM 67186 to 67190, RBINS INV 138033 to $138034 \cdot 3$ ô $\hat{0}, 6$ 우; same collection data as for holotype; in EtOH as bulk paratypes; WAM 67191.

\section{Other material}

AUSTRALIA - Western Australia - Lake Carey - 2 spec.; Goldfields; 28 $57^{\prime} 05^{\prime \prime}$ S, $122^{\circ} 16^{\prime} 58^{\prime \prime}$ E [approximate coordinates]; 2 Apr. 1999; Shane Chaplin leg.; WAM 67197 to 67198. - Lake Lefroy

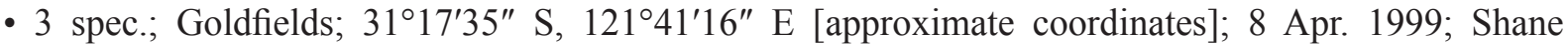

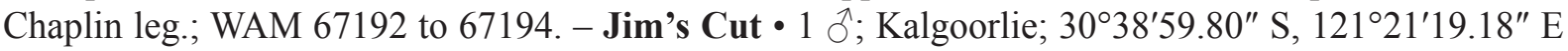
[approximate coordinates]; 12 Jul. 2012; Sabrina Arklie leg.; WAM 67195. - Lake Disappointment • $1 \mathrm{O}^{\top}$; Little Sandy Desert; $23^{\circ} 24^{\prime} 50^{\prime \prime} \mathrm{S}, 122^{\circ} 57^{\prime} 01^{\prime \prime} \mathrm{E}$ [approximate coordinates]; 7 Jan. 2016; Michael Curran leg.; WAM 67196.

\section{Measurements}

See Table 1.

\section{Description}

Male

RV (Fig. 2B). Highly arched, with greatest height situated behind the middle; anterior margin rounded, slightly produced, dorsal margin straight and anteriorly sloping over a short distance, posterior margin broadly rounded, ventral margin slightly sinuous in middle, few very small marginal tubercles on posterior half of ventral margin. In inner view, anterior calcified inner lamella relatively narrow, and devoid of selvage or inner list. Posterior calcified inner lamella even narrower and with inner list in its top half, inner margin of posterior calcified inner lamella slightly elevated.

LV (Fig. 2A). With shape similar to that of RV, slightly larger. In inner view, anterior calcified inner lamella slightly wider than in RV, but also without selvage or inner list. Posterior calcified inner lamella narrow and with a remnant of an inner list in its upper half. All margins devoid of marginal tubercles.

CARAPACE. In lateral view (Fig. 2C) showing LV overlapping RV on all sides, but especially along posterior margin. External rimmed pores present (Fig. 2F). In dorsal view (Fig. 2I-J) showing greatest width in middle, anterior part (Fig. 2H) relatively symmetrical and convex.

A1 (Fig. 3A-C). 7-segmented, generally with robust appearance; all segments relatively short and broad; chaetotaxy typical of subfamily.

A2 (Fig. 4A, D). With chaetotaxy typical of subfamily; natatory setae reaching slightly beyond tips of end claws. Accompanying seta of aesthetasc y3 about $1 / 3$ longer than aesthetasc. Seta $g$ and claw Gm almost of equal length. 
MD (Fig. 3D). As typical of family. Palp (not drawn) with alpha seta long and thin, set with setulae in proximal half; beta seta longer than alfa seta and set with setulae over most of its length and gamma seta stout and distally pointed, set with setulae on distal half.

Mx1 paLp (Fig. 4C). With chaetotaxy typical of family; second palp segment slightly longer than basal width and slightly curved. Third endite of Mx1 (Fig. 4C) with Zahnborsten carrying 5-6 spines on ventral side only.

Prehensile PalPs ON T1. Asymmetrical, chaetotaxy of endopodite typical of family (not shown - but see Fig. 3E for female chaetotaxy of this limb). Rpp (Fig. 5B) with first segment widening distally, with two small sensory organs at ventro-distal edge. Distal segment sub-triangular, ventrally bluntly pointed, distal margin almost straight, with additional lapel-like process at proximo-dorsal edge. Lpp (Fig. 5C) with proximal margin of first segment broad, distal margin only ca $1 / 4$ of proximal margin, comprising short length of attachment of second segment; long ventro-distal edge set with two tubercles and two

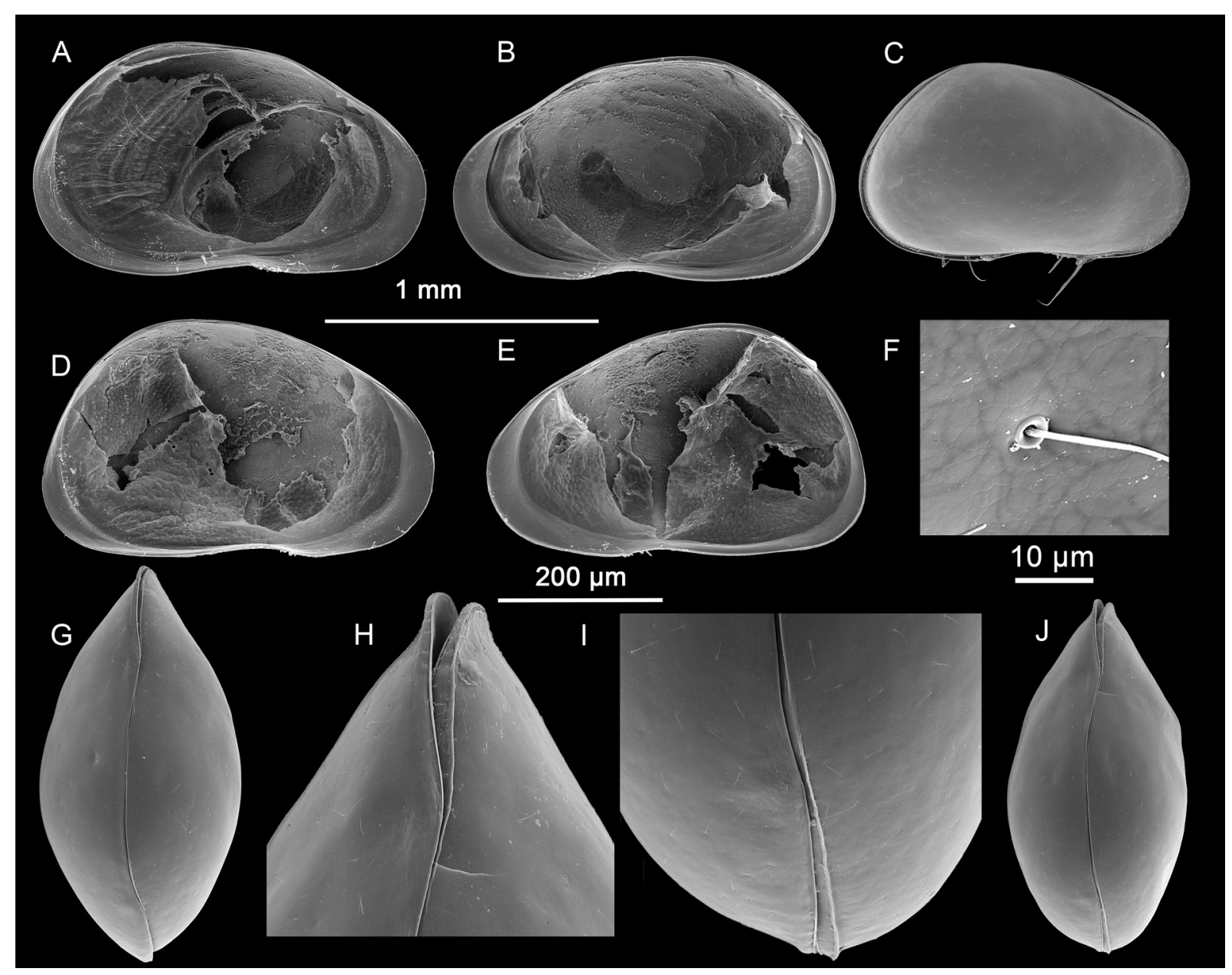

Fig. 2. Patcypris outback gen. et sp. nov., Lake Maitland (type locality). A. LVi, ð, holotype (WAM 67184). B. RVi, Ô, holotype (WAM 67184). C. CpRL, ô, paratype, small specimen (WAM 67188). D. LVi, + , allotype (WAM 67185). E. RVi,, , allotype (WAM 67185). F. CpRL, ô, paratype, detail of external rimmed pore on RV (WAM 67188). G. CpD, + , paratype (WAM 67187). H. CpD, ô, paratype, detail anterior (WAM 67189). I. CpD, ô, paratype, detail posterior (WAM 67189). J. CpD, ô, paratype (WAM 67189). Scales: A-E, G, J = $1 \mathrm{~mm} ; \mathrm{F}=10 \mu \mathrm{m} ; \mathrm{H}-\mathrm{I}=200 \mu \mathrm{m}$. 


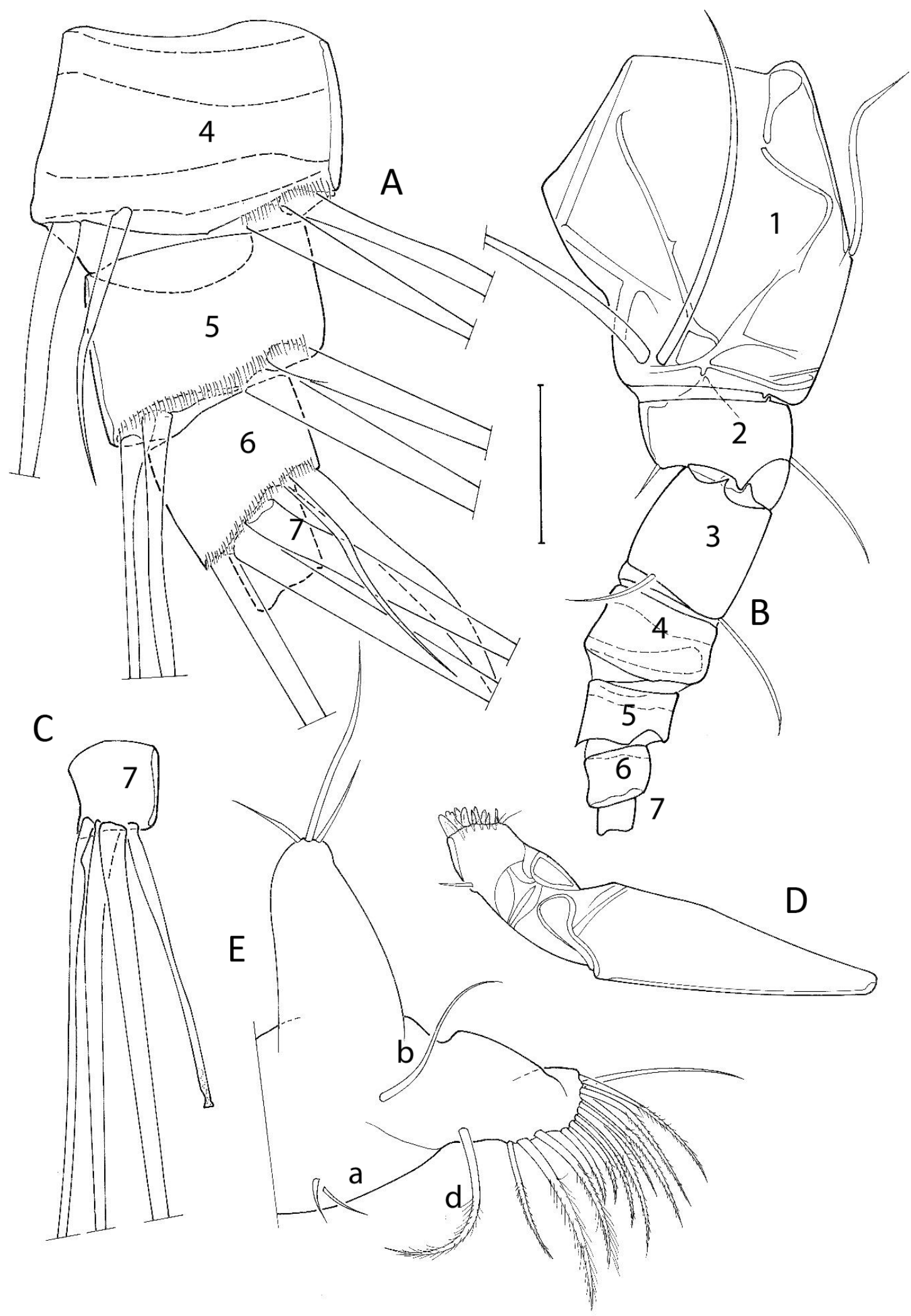

Fig. 3. Patcypris outback gen. et sp. nov., Lake Carey. A-C. $\partial$ (WAM 67197). A. A1, showing chaetotaxy of segments 4-6. B. A1, showing chaetotaxy of segments 1-3. C. A1, showing chaetotaxy of segment 7. D-E. + (WAM 67198). D. Md coxa. E. T1 (respiratory plate not shown). Scale: A, C = $37 \mu \mathrm{m} ; \mathrm{B}, \mathrm{E}=$ $92 \mu \mathrm{m} ; \mathrm{D}=232 \mu \mathrm{m}$. 
sensory organs. Second segment narrow and curved, without flagellum-like expansion but with distal point swollen.

T2 (Fig. 7B). With penultimate segment divided, proximally only seta $\mathrm{d} 1$ present, seta $\mathrm{d} 2 \mathrm{absent}$.

T3 (not shown). A cleaning limb, as typical of family.

CR (Fig. 5D). Curved and proximally expanded; claws relatively short.

AtTACHMENT To CR (Fig. 7A). Long, narrow and uniramous.

ZENKER ORGAN (not shown). Typical of family, i.e., ca 3-5 $\times$ as long as wide and with numerous spinous whorls.

HemipenIs (Fig. 5A). Large, wide and with two distal lobes: lobe ms large and distally bilobed, lobe 1s shaped like a pickaxe, with long, stout and pointed ventral point and upturned dorsal extremity.

\section{Female}

VALVES (Fig. 2D-E). With shape similar to those of male, but with dorsal side more rounded and with postero-ventral corner in both valves more produced. Valve margin anatomy as in male. Carapace in dorsal view (Fig. 2G) as in male.

A1, Md, Mx1, T2, T3 and attachment of CR as in male.

A2 (Fig. 4B). With distal chaetotaxy showing sexual dimorphism as typical of family.

T1 (Fig. 3E). With palp not segmented, relatively short and broad. Chaetotaxy of endopod as typical of family.

CR (Fig. 5E). With proximal part even more dilated than in male.

\section{Differential diagnosis}

As for the genus. In addition, the shape of the two lobes of the hemipenis and the presence of the additional process on the second segment of the Rpp are unique within the Cyprinotinae.

\section{Ecology and distribution}

Patcypris outback gen. et sp. nov. occurs in shallow playas of inland Western Australia across a latitudinal range of more than $900 \mathrm{~km}$. Rainfall in these areas is low and variable, with an annual mean of 200-300 mm. Patcypris outback gen. et sp. nov. appears to be a halophile. A report by Outback Ecology from 2011 (not publicly available) stated that its upper salinity tolerance is $145 \mathrm{mS} \mathrm{cm}^{-1}$ (approximately $150000 \mathrm{mg} \mathrm{L}^{-1} \mathrm{TDS}$ ) and Lakes Maitland, Carey, Lefroy and Disappointment are mostly hypersaline when filled (no information about Jim's Cut is available). Specimens from Lake Disappointment hatched at a salinity of $5000 \mathrm{mg} \mathrm{L}^{-1}$.

\section{Remarks}

The shape of the additional elongated process on the second segment of the Rpp is somewhat variable. In addition to being rather broad and distally rounded, as in Fig. 5B, this protrusion was bluntly to even acutely pointed in other specimens. 


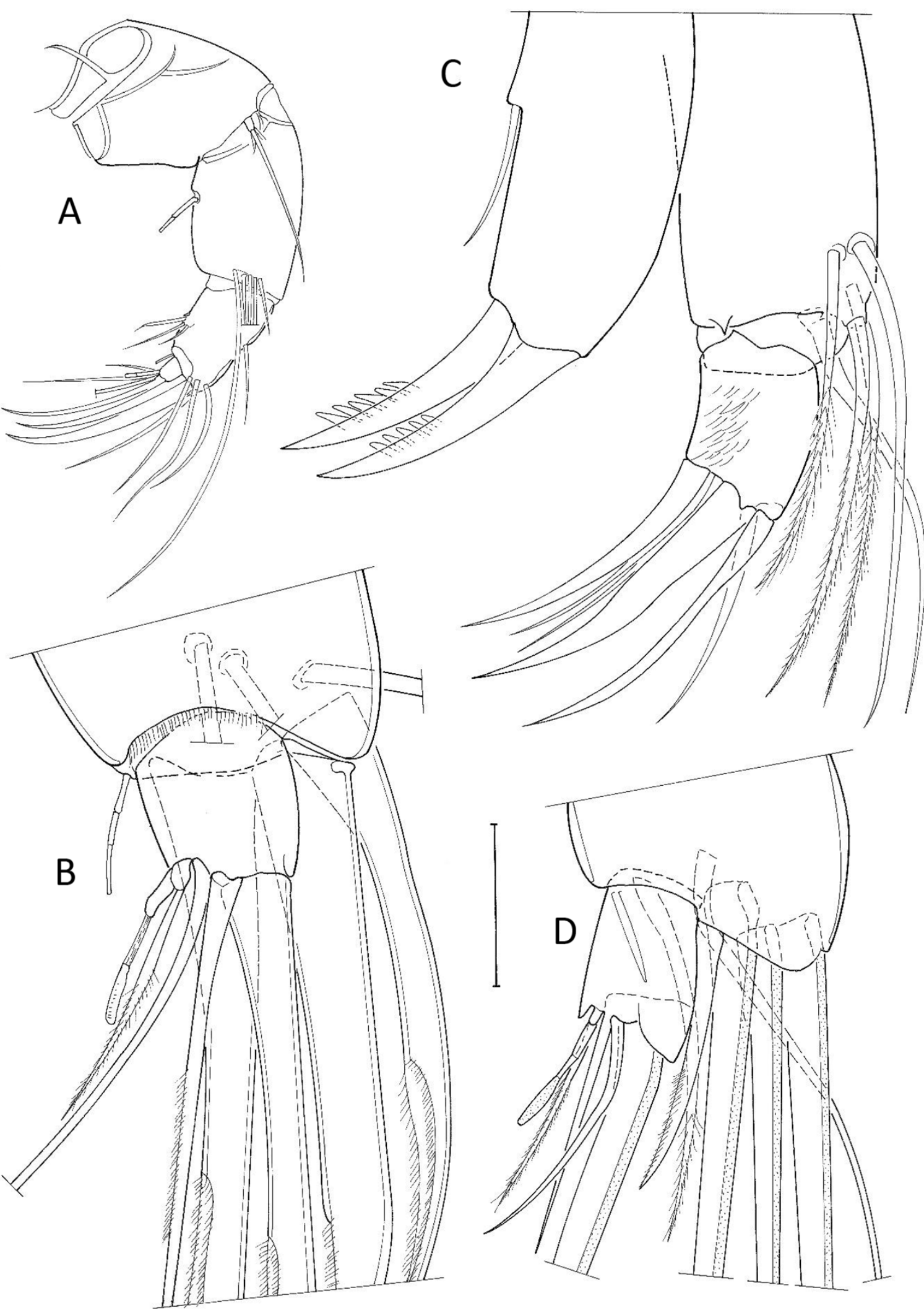

Fig. 4. Patcypris outback gen. et sp. nov., Lake Carey. A-C. ㅇ (WAM 67198). A. A2. B. A2, distal chaetotaxy. C. Mx1, palp and $3^{\text {rd }}$ endite showing Zahnborsten. D. $\hat{o}$ (WAM 67197), A2, distal chaetotaxy. Scale: $\mathrm{A}=232 \mu \mathrm{m} ; \mathrm{B}-\mathrm{D}=37 \mu \mathrm{m}$. 


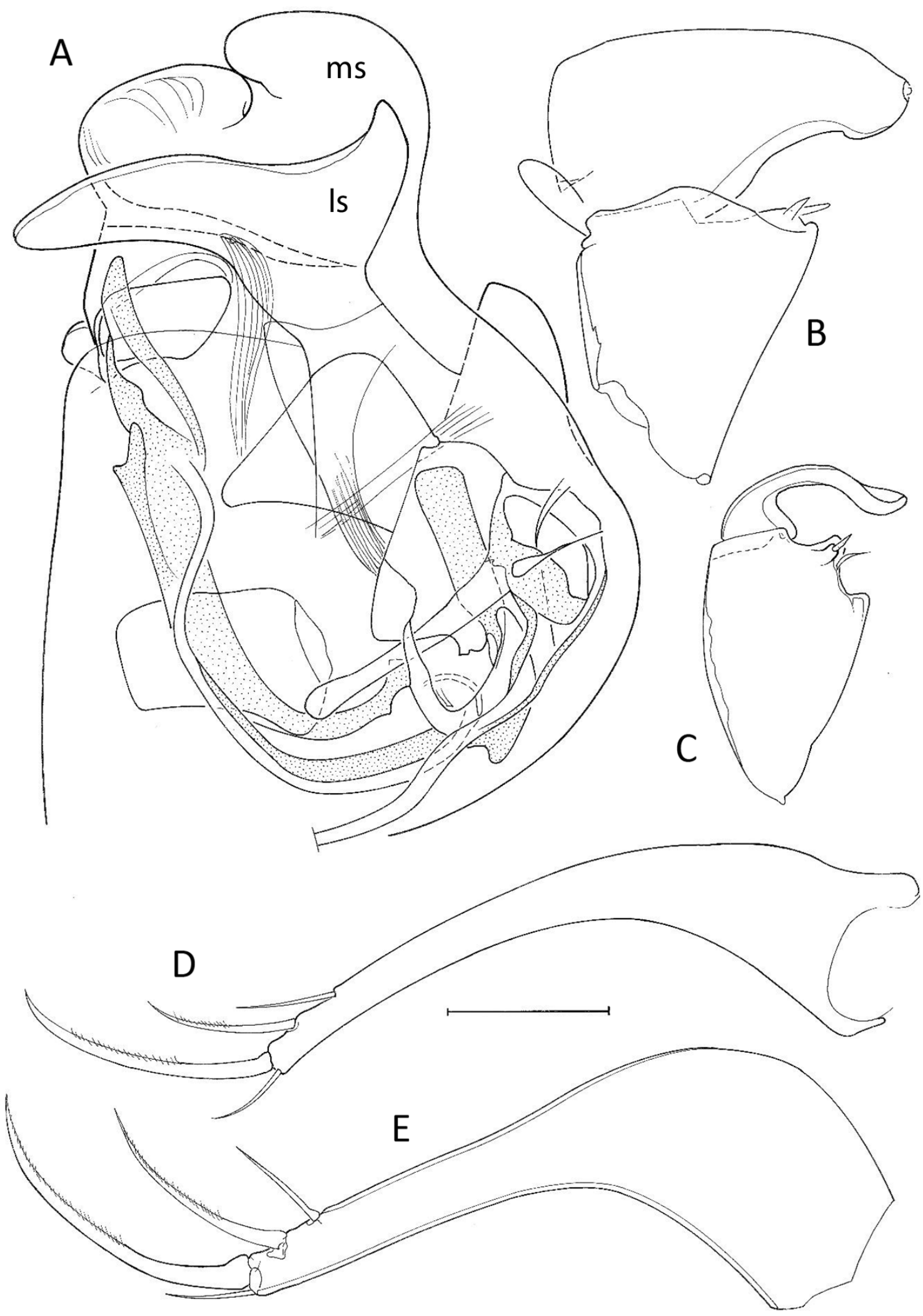

Fig. 5. Patcypris outback gen. et sp. nov. A-C. O’, holotype (WAM 67184) from Lake Maitland (type locality, sample LN5217). A. Hp. B. Rpp. C. Lpp. D. CR, ð (WAM 67197) from Lake Carey (sample OSTR60C). E. CR, o (WAM 67198) from Lake Carey (sample OSTR60C). Scale $=92 \mu \mathrm{m}$. 


\section{Trilocypris gen. nov. urn:1sid:zoobank.org:act:80ACCA78-B7FD-4D37-BEA3-252915BAEBAD}

\section{Type species}

Trilocypris horwitzi gen. et sp. nov. (here designated).

\section{Other species}

The genus is thus far monospecific.

\section{Diagnosis}

Valves high posteriorly, moderately arched, LV overlapping RV on all sides. RV with marginal tubercles (sometimes strongly developed) at least along anterior and postero-ventral margins and an outer list. RV with anterior sub-marginal selvage only; posteroventral selvage more clearly inwardly displaced. LV anteriorly with a blunt inner list parallel to valve margin. A1 with all segments of normal length/width ratio.Second segment of Mx1 palp slightly longer than basal width, not curved. Second segment on Lpp with long distal flagellum. Seta $\mathrm{d} 2$ on T2 absent. CR in both male and female proximally curved, but without swollen proximal side; attachment to CR uniramous, i.e., distally not bifurcated. Hemipenis in males with three distal lobes.

\section{Etymology}

This new genus is named after one of its most defining characters, namely the fact that the hemipenis in the male has three distal lobes (instead of two as in other Cyprinotinae). We shortened 'trilobe' to 'trilo' for convenience.

\section{Differential diagnosis}

Trilocypris gen. nov. has valve characteristics that are similar to those of Heterocypris, but differs from all other genera in the Cyprinotinae by the structure of the hemipenis, which has three distal lobes. This is unique in the subfamily Cyprinotinae, and possibly even in the entire family Cyprididae.

The new genus can furthermore be distinguished from Cyprinotus by the absence of the dorsal hump on the right valve, from Hemicypris and Homocypris by the fact that the LV overlaps the RV (inverse in Hemicypris; valves symmetrical in Homocypris) and from Riocypris by, among other features, the absence of seta $\mathrm{d} 2$ on $\mathrm{T} 2$.

\section{Distribution}

Currently known from the Yilgarn region of Western Australia only.

\section{Remarks}

As usual in monospecific genera, it is difficult to determine which characters are valid at the generic level and which at the specific level. The diagnosis of this new genus may need to be adapted if more congeneric species are found.

Trilocypris horwitzi gen. et sp. nov. urn:lsid:zoobank.org:act:39E852F5-6D42-4412-8004-F721C6861F87

Figs $6,7 \mathrm{C}-\mathrm{G}$

\section{Diagnosis}

Valves higher in posterior half than anterior, but with greatest height situated in middle. RV with both anterior and posterior sub-marginal selvage, posterior one somewhat more inwardly displaced 
than anterior one; anterior and posteroventral margins set with medium-sized marginal tubercles. LV anteriorly with blunt inner list (more like an elevation), posteriorly with inner list in top part of calcified inner lamella. Carapace in dorsal view with anterior rostrum. Rpp without additional protrusion on sub-triangular second segment. Lpp with almost rectangular first segment, but with rounded expansion in distal part of ventral margin; second segment sickle-shaped and with long, thin apical flagellum. Hemipenis with lobe ls boot-shaped; lobe ms asymmetrically rounded; additional lobe os rounded and pustulose; distal part of bc small and sickle-shaped, distally pointed.

\section{Etymology}

This new species is named in honour of Prof. Pierre Horwitz (Edith Cowan University, Perth, Australia), who collected the present material, in recognition of his outstanding contributions to Western Australian limnology.

\section{Measurements}

See Table 1 .

\section{Type locality}

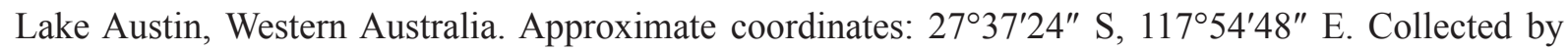
P. Horwitz, 1 Oct. 1997.

\section{Material examined}

\section{Holotype}

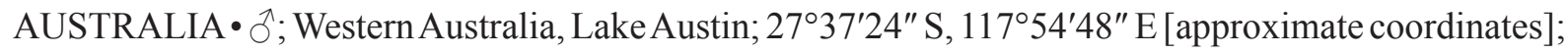
1 Oct. 1997; P. Horwitz leg.; with soft parts dissected in glycerine on a sealed slide and with valves stored dry in a micropalaeontological slide; WAM 67199.

\section{Allotype}

AUSTRALIA - +; same collection data as for holotype; dissected and stored as the holotype; WAM 67200.

\section{Paratypes}

AUSTRALIA 1 1 ; same collection data as for holotype; dissected and stored as the holotype; WAM 67201 - 3 female carapaces; same collection data as for holotype; used for SEM and stored in a

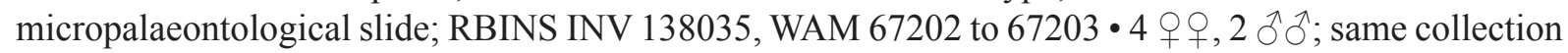
data as for holotype; in EtOH as bulk paratypes; WAM 67204.

\section{Other material}

This species has recently been collected from a small number of salt lakes around the type locality. Some of these specimens show slight morphological differences from the specimens described here.

\section{Description}

\section{Male}

RV (Fig. 6B). With anterior margin rounded and with greatest height in middle; dorsal margin sloping in anterior third, then straight, posterior margin straight, then broadly rounded in ventral half, ventral margin slightly sinuous in middle. RV with both anterior and posteroventral sub-marginal selvages, posterior one somewhat more inwardly displaced than anterior one, anterior and posteroventral margins set with medium-sized marginal tubercles. Calcified inner lamellae narrow, more so posteriorly; both lamellae without inner lists. 
HALSE S.A. \& MARTENS K., New genera and species of "Heterocypris" from Western Australia

LV (Fig. 6A). Generally with shape comparable to that of RV, slightly larger. In inner view, anterior calcified inner lamella slightly wider than in RV. Anteriorly with blunt inner list running parallel to most of valve margin, posteriorly with blunt inner list in top part of calcified inner lamella.

CARAPACE. In dorsal and ventral views (Fig. 6 F, H-J) with weak anterior rostrum; greatest width situated in middle. In lateral view with prominent anterior LV/RV overlap (illustrated for females in Fig. 6C).

PREHENSILE PALPS ON T1. Asymmetrical, chaetotaxy of endopodite as typical for family (not shown). Rpp (Fig. 7D) with subtriangular second segment as in previous species, but without additional process on dorso-proximal corner. Lpp (Fig. 7E) with nearly rectangular first segment, except for rounded distal part of ventral margin. Second segment sickle-shaped and narrow, with distal flagellum-like expansion.

ZENKER ORGAN. As typical of family, i.e., ca 3-5 $\times$ as long as wide and with numerous spinous whorls.

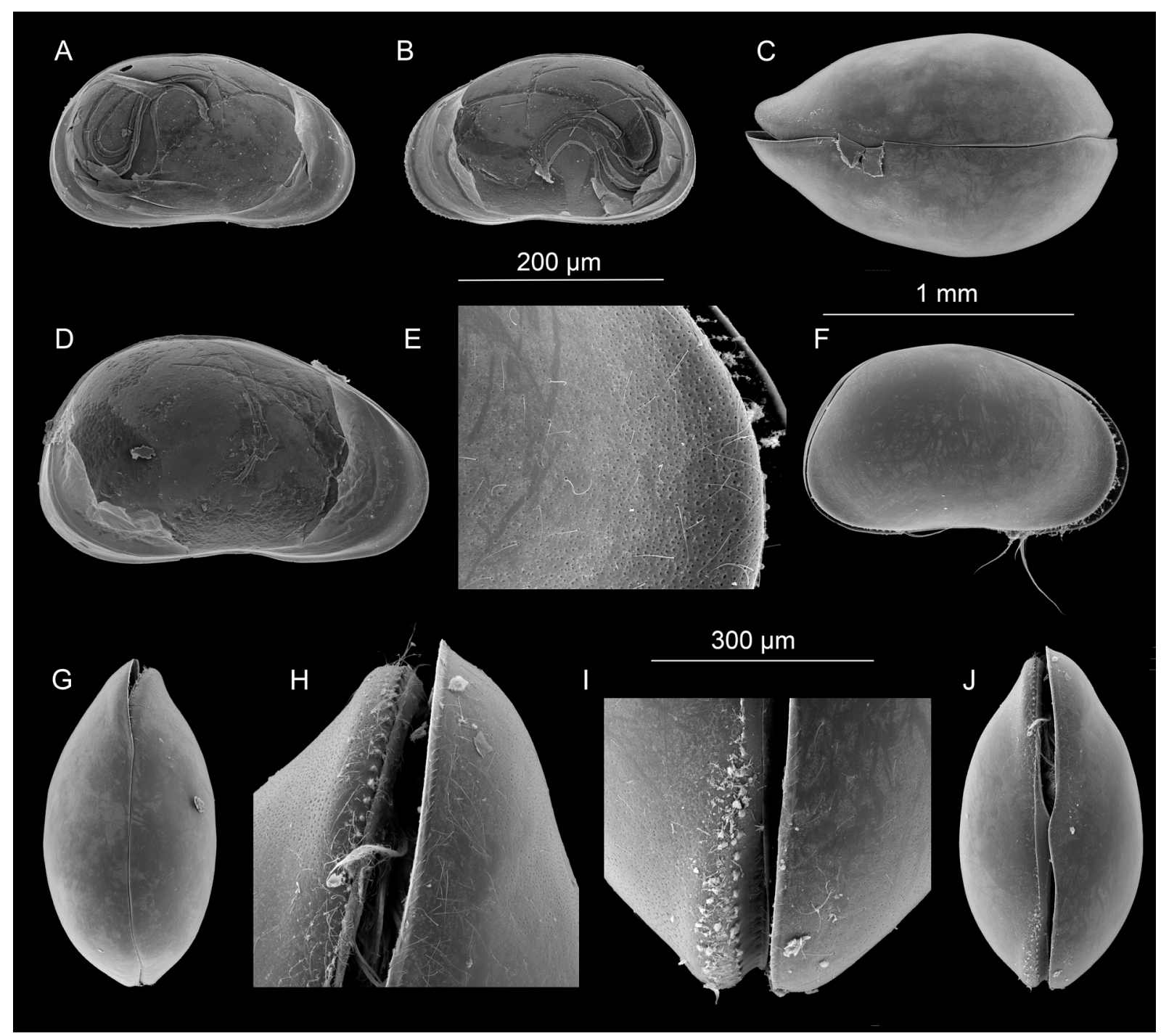

Fig. 6. Trilocypris horwitzi gen. et sp. nov., Lake Austin (type locality). A. LVi, $\widehat{\jmath}$, holotype (WAM 67199). B. RVi, Õ, holotype (WAM 67199). C. CpD, o (WAM 67203). D. LVi, o, allotype (WAM 67200). E. CpRL, anterior detail, ô (RBINS INV 138035). F. CpRL, ô (RBINS INV 138035). G. CpD, $\lesssim$ (specimen lost). H. CpV, anterior detail, $\lesssim$ (WAM 67203). I. CpV, posterior detail, $\lesssim$ (WAM 67203). J. CpV, $\widehat{\jmath}$ (WAM 67203). Scale: A-D, F-G, J = 1 mm; E = $200 \mu \mathrm{m} ; \mathrm{H}-\mathrm{I}=300 \mu \mathrm{m}$. 


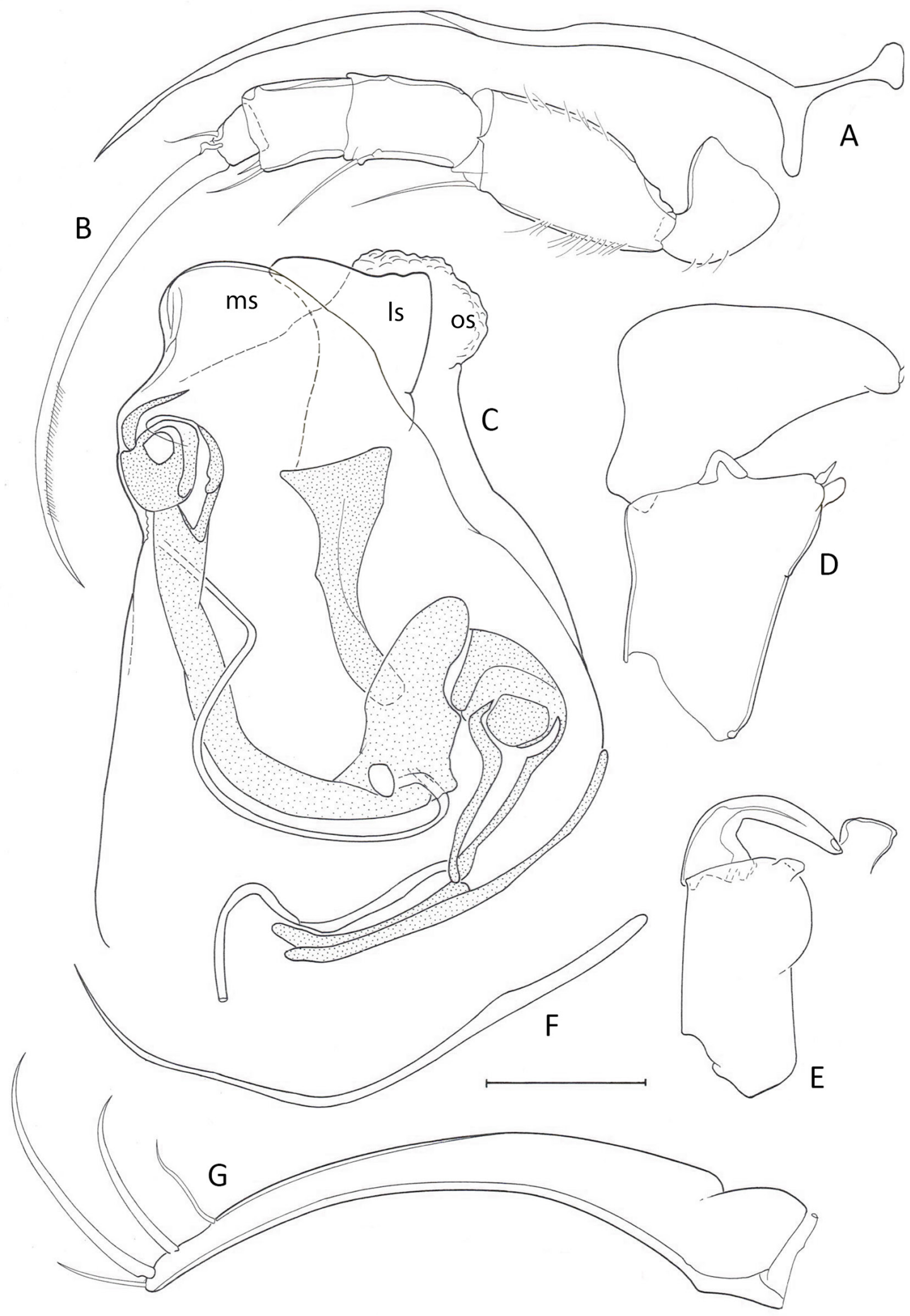

Fig. 7. A-B. Patcypris outback gen. et sp. nov., Lake Maitland (type locality), $\widehat{\jmath}$, holotype (WAM 67184). A. CR attachment (note: the bifurcation to the right is the basis of the CR itself). B. T2. - C-G. Trilocypris horwitzi gen. et sp. nov., Lake Austin (type locality), đ̂, holotype (WAM 67199). C. Hp. D. Rpp. E. Lpp. F. CR attachment. G. CR. Scale $=92 \mu \mathrm{m}$. 
HALSE S.A. \& MARTENS K., New genera and species of "Heterocypris" from Western Australia

HemiPENIS (Fig. 7C). With 1s boot-shaped, with ventrally directed blunt point; ms evenly rounded, additional lobe os rounded and pustulose. Extremity of internal bc small and sickle-shaped, with pointed tip.

Caudal Ramus (Fig. 7G). Curved and proximally less expanded than in previous species. Its attachment (Fig. 7F) uniramous.

\section{Female}

VALVES (Fig. 6D). With shape similar to that of male. Valve margin anatomy as in male.

CARAPACE (Fig. 6G). Somewhat wider than in male, but also with weak rostrum.

A1, Md, Mx1, T2, T3 and attachment of CR as in male.

A2 (not shown). With distal chaetotaxy showing sexual dimorphism as typical of family.

T1 (not shown). With palp not segmented, relatively elongated.

\section{Differential diagnosis}

As for genus. Specifically, the structure and shape of the three hemipenis lobes are, to the best of our knowledge, different from that in all other species in the Cyprinotinae.

\section{Ecology and distribution}

Trilocypris horwitzi gen. et sp. nov. is known only from Lake Austin, a large, shallow saline pan situated more than $400 \mathrm{~km}$ from the coast, and some smaller pans in its immediate vicinity. Trilocypris horwitzi gen. et sp. nov. was hatched from Lake Austin sediment and collected from the hatching aquaria at salinities between 0.3 and $67.1 \mathrm{mS} \mathrm{cm}^{-1}$ (approximately 200 and $45000 \mathrm{mg} \mathrm{L}^{-1}$ ). At the time the sediment was collected, Lake Austin was flooded and water salinity in the lake and pans varied from $23000 \mathrm{mg} \mathrm{L}^{-1}$ to supersaturation. Some additional individuals of Trilocypris horwitzi gen. et sp. nov. were collected, but the salinity where they occurred was not recorded.

Bilocypris gen. nov. urn:1sid:zoobank.org:act:5A47A7DD-B9FE-4703-9941-38EA85B53280

\section{Type species}

Bilocypris fortescuensis gen. et sp. nov. (here designated).

\section{Other species}

Bilocypris mandoraensis gen. et sp. nov.

\section{Diagnosis}

Valves higher in posterior half than anterior, LV overlapping RV on all sides. RV with marginal tubercles at least along anterior and postero-ventral margins; in between these zones RV with outer list; these marginal tubercles sometimes strongly developed. RV with anterior selvage sub-marginal and with posteroventral selvage more clearly inwardly displaced. LV anteriorly with blunt inner list parallel to valve margin. A1 with all segments of normal length/width ratio. Second segment of Mx1 palp slightly longer than basal width, not curved. Seta $\mathrm{d} 2$ on T2 absent. CR in both male and female moderately curved and slightly expanded in proximal part; attachment to CR uniramous, i.e., distally not bifurcated. Hemipenis in males with lobe ms bilobed, lobe ls of equal length to ms. Females in both species in this genus with large, rounded genital lobes. 


\section{Etymology}

The name of this new genus refers to the fact that lobe ms of the hemipenis is bilobed. We have abbreviated 'bilobe' to 'bilo' for convenience.

\section{Differential diagnosis}

Bilocypris gen. nov. has valve characteristics that are similar to those in Heterocypris, but differs from all other genera in the Cyprinotinae by the structure of the hemipenis, which consists of a bilobed ms and a lobe ls of the same length as the ms.

The new genus can be distinguished from Cyprinotus by the absence of the dorsal hump on the RV, from Hemicypris and Homocypris by the fact that the LV overlaps the RV (inverse in Hemicypris; valves symmetrical in Homocypris) and from Riocypris by the absence of seta $\mathrm{d} 2$ on limb $\mathrm{T} 2$, among other features.

\section{Distribution}

Both species in the genus are known from northwest Western Australia (Pilbara and southern Kimberley regions).

Bilocypris fortescuensis gen. et sp. nov. urn:1sid:zoobank.org:act:9354F295-A5CF-4DB4-A1B1-9DA925F677E9

Figs 8-9

\section{Diagnosis}

Valves arched, greatest height situated in middle. RV with anterior and posterior marginal selvage. Large marginal tubercles present along anterior, postero-ventral and posterior margins. Lpp with elongated first and second segment; first segment with sub-parallel margins; second segment sickle-shaped and with flagellum-like distal part. Hemipenis with lobe ls spatulate rather than boot-shaped, and with distal margin almost straight; lobe ms bilobed; distal part of bc long, stout and pointed.

\section{Etymology}

Named after the type locality, Fortescue Marsh, Pilbara, Western Australia.

\section{Measurements}

See Table 1.

\section{Type locality}

Fortescue Marsh, Pilbara, Western Australia. Approximate coordinates: 22 $30^{\prime} 48^{\prime \prime} \mathrm{S}, 119^{\circ} 46^{\prime} 41^{\prime \prime} \mathrm{E}$. Collected by Jane McRae and Adrian Pinder, 16 Aug. 2003 (sample PSW002). Subsequent collections made by S. Halse, I. Schön and K. Martens, 24 Apr. 2006 (sample KIES11).

\section{Material examined}

\section{Holotype}

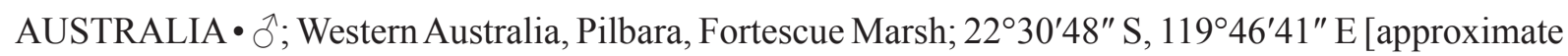
coordinates]; 16 Aug. 2003; Jane McRae and Adrian Pinder leg.; sample PSW002; dissected, with soft parts stored in glycerine on a sealed slide and valves stored dry in a micropalaeontological slide; WAM 67205 .

\section{Allotype}

AUSTRALIA - + ; same collection data as for holotype; dissected and stored as the holotype; WAM 67206. 


\section{Paratypes}

AUSTRALIA • 1 ; ; same collection data as for holotype; dissected and stored as the holotype; WAM 67207 - 2 female carapaces; same collection data as for holotype; used for SEM and stored in a micropalaeontological slide; WAM 67208 to $67209 \cdot 1$ ô, 3 우; same collection data as for holotype; in EtOH as bulk paratypes; WAM 67211 - 1 ; ; same locality as for holotype; 24 Apr. 2006; S. Halse, I. Schön and K. Martens leg.; sample KIES11; with valves stored dry in micropalaeontological slide and with soft body successfully used for DNA extraction; RBINS INV $138036 \bullet 1$ ○; same collection data as for preceding; used and stored as preceding; WAM $67214 \cdot 2 \hat{\jmath}$; ; same collection data as for preceding; carapaces used for SEM and stored dry in micropalaeontological slides; WAM 67212 to $67213 \cdot 3$ 우; same collection data as for preceding; used and stored as preceding; WAM 67215 to 67216 , RBINS INV 138037. The bulk sample of sample KIES11 was lost.

\section{Description}

Male

RV (Fig. 8B). Arched, greatest height situated in middle; anterior margin rounded, posterior margin nearly straight, ventral margin weakly sinuous in middle. With both anterior and posteroventral submarginal selvages, anterior and posteroventral margins set with medium-sized marginal tubercles. Anterior calcified inner lamella relatively wide, posterior lamella narrow; both lamellae without inner lists.

LV (Fig. 8A). Generally with shape as in RV, slightly larger. Anterior calcified inner lamella slightly wider than in RV, blunt anterior inner list running parallel to most of valve margin, posteriorly with blunt inner list in top part of calcified inner lamella.

CARAPACE. In dorsal (Fig. 8J, M) and ventral views (see Fig. 8C, E, of female carapace) with weak anterior rostrum; greatest width situated in middle. In lateral view (Fig. $8 \mathrm{H}$ ) with anterior LV/RV overlap prominent (illustrated for females in Fig. 8G, I).

Prehensile palps on T1. Asymmetrical, chaetotaxy of endopodite as typical for family (not shown). Rpp (Fig. 9C) with second segment as in previous species, also without the additional protrusion on dorso-proximal corner. First segment expanding distally, with two ventro-distal lobes, each supporting a sensory organ. Lpp (Fig. 9B) with nearly rectangular first segment, ventro-distal lobes narrow and bluntly pointed; second segment sickle-shape and narrow, with long distal, flagellum-like expansion.

ZENKER ORGAN. As typical of family, i.e., ca 3-5 $\times$ as long as wide and with numerous spinous whorls.

HemiPENIs (Fig. 9A). With 1s spatulate, with distal margin nearly straight; ms bilobed as a result of distal indentation, a small additional rounded 'lobe' present on ventral side of ms; distal part of internal bc stout and elongated, with pointed tip.

Caudal Ramus (Fig. 9E). Curved; its attachment (Fig. 9D) uniramous.

\section{Female}

VAlves (Fig. 8D-E). With shape similar to that of male. Valve margin anatomy as in male, except for more inwardly displaced posteroventral selvage in LV.

CARAPACE. In ventral (Fig. 8K) and dorsal (Fig. 8L) views as in male.

$\mathrm{A} 1, \mathrm{Md}, \mathrm{Mx} 1, \mathrm{~T} 2, \mathrm{~T} 3$ and attachment of $\mathrm{CR}$ as in male.

A2 (not shown). With distal chaetotaxy showing sexual dimorphism as typical of family. 
T1 (not shown). With palp not segmented, relatively elongated.

GeNITAL LOBEs. Large and with rounded distal and sub-parallel lateral margin.
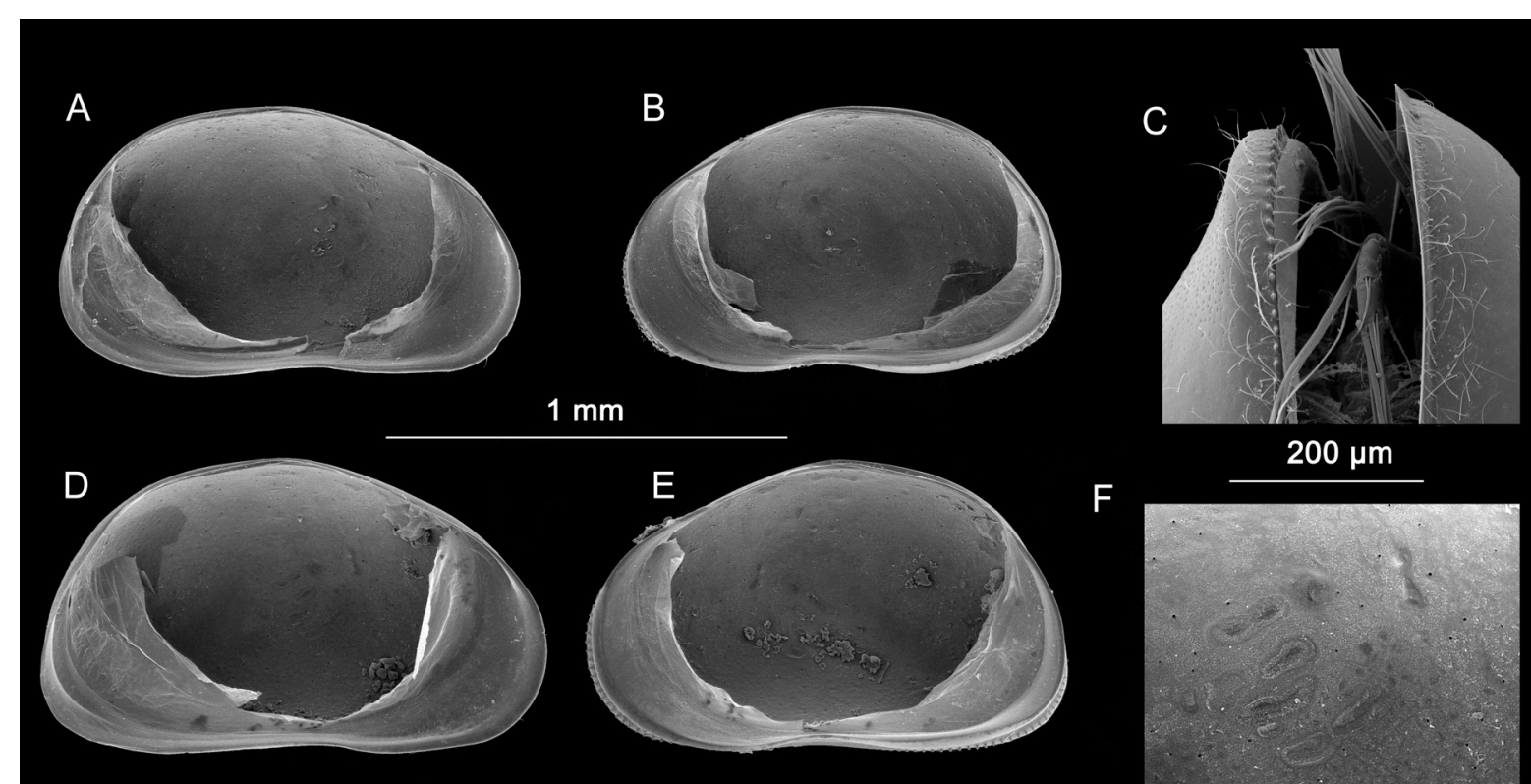

F
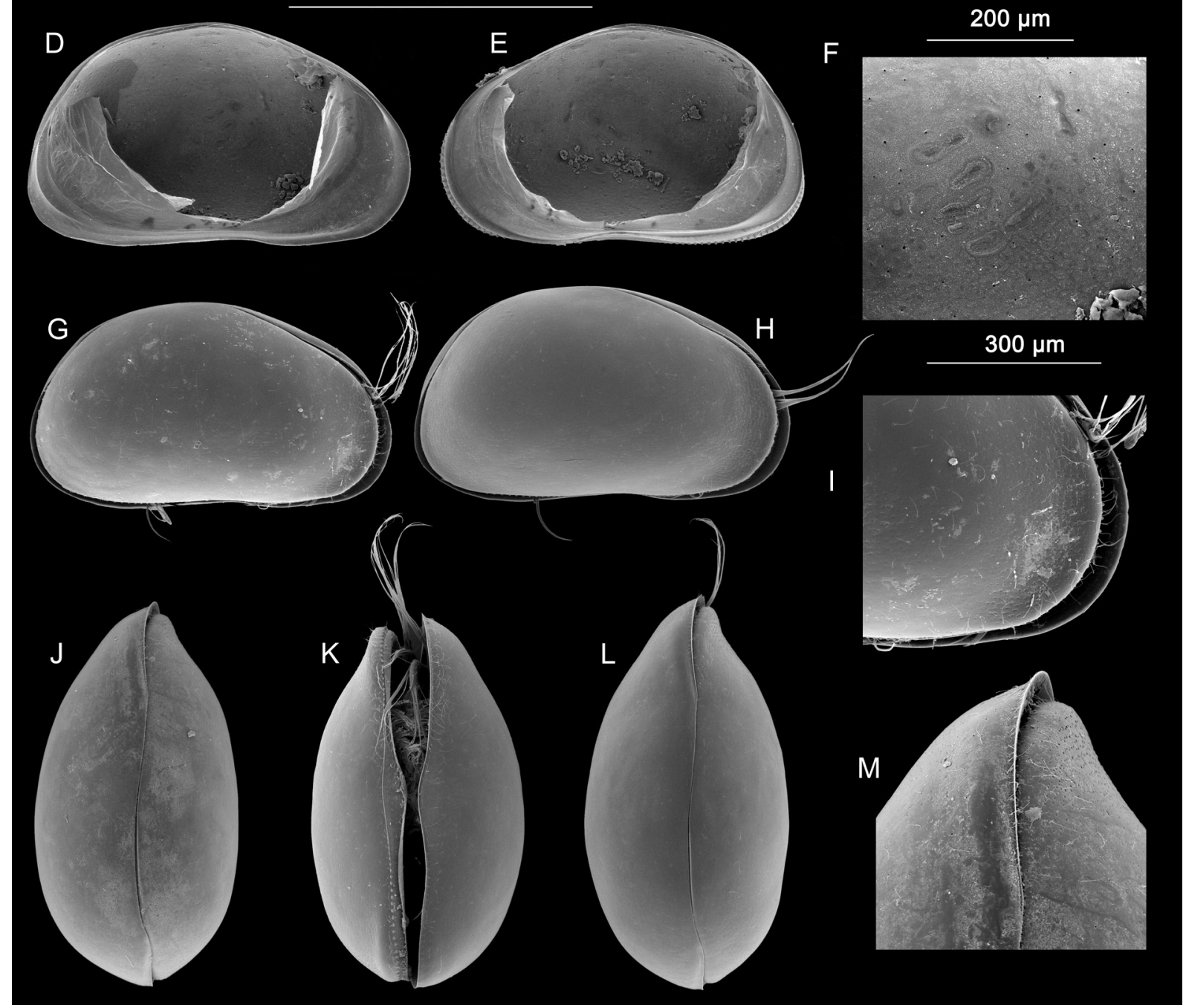

Fig. 8. Bilocypris fortescuensis gen. et sp. nov., Forstescue Marsh (type locality). A. LVi, §, holotype

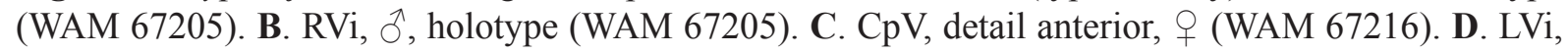
, allotype (WAM 67206). E. RVi, ㅇ, allotype (WAM 67206). F. RVi, + , detail central muscle scars, allotype (WAM 67206). G. CpRL, $\widehat{O}$ (WAM 67212). H. CpRL, + (WAM 67215). I. CpRL, detail anterior, + (WAM 67212). J. CpD, $ð$ (WAM 67213). K. CpV, o (WAM 67216). L. CpD, $q$ (RBINS INV 1380377). M. CpD, detail anterior, ठ (WAM 67213). Scales: A-B, D-E, G-H, J-L = $1 \mathrm{~mm}$; C, F, $\mathrm{M}=200 \mu \mathrm{m} ; \mathrm{I}=300 \mu \mathrm{m}$. 


\section{Differential diagnosis}

Bilocypris fortescuensis gen. et sp. nov. is closely related to B. mandoraensis gen. et sp. nov. (see below), but can be distinguished from it by its smaller size, less pronounced bilobed nature of the lobe ms of the hemipenis, the shape of lobe ls (spatulate in B. fortescuensis gen. et sp. nov., pointed boot-shaped in B. mandoraensis gen. et sp. nov.) and the shape of the second segment of the Rpp (robust and subtriangular in B. fortescuensis gen. et sp. nov., more elongated, with a skewed shape in B. mandoraensis gen. et sp. nov.).

\section{Ecology and distribution}

Bilocypris fortescuensis gen. et sp. nov. has been collected only from Fortescue Marsh, a very large mostly hyposaline playa in the central Pilbara region of Western Australia. The marsh floods every few years and holds water for up to six months. Bilocypris fortescuensis gen. et sp. nov. has been recorded at salinities of 3400 and $12000 \mathrm{mg} \mathrm{L}^{-1}$ TDS (Pinder et al. 2010).

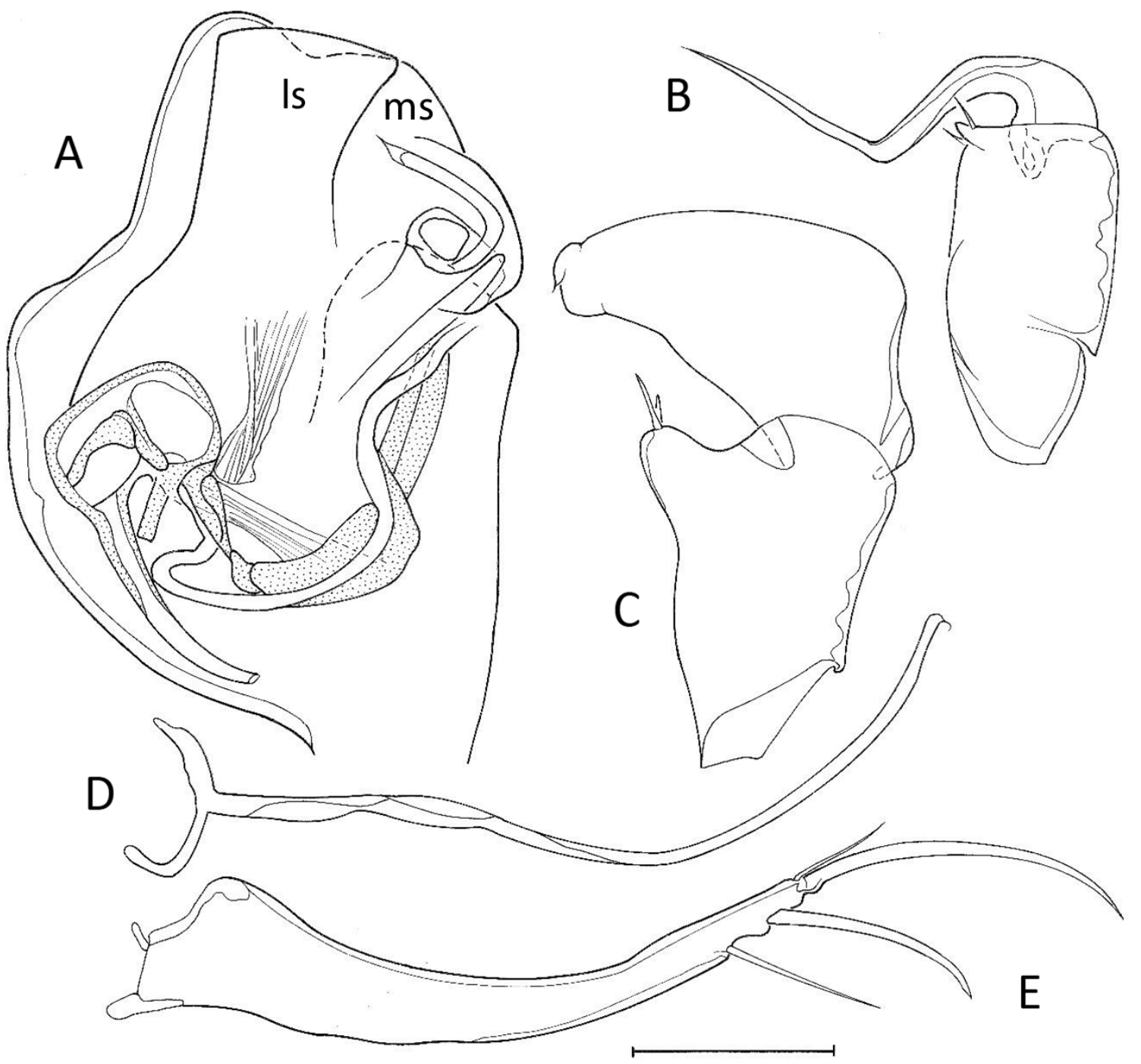

Fig. 9. Bilocypris fortescuensis gen. et sp. nov., Ô, holotype (WAM 67205), from Forstescue Marsh (type locality, sample PSW002). A. Hp. B. Lpp. C. Rpp. D. CR attachment (note: the bifurcation at the left side is the basis of the actual CR). E. CR. Scale $=92 \mu \mathrm{m}$. 


\section{Remarks}

No male soft parts of the KIES11 material could be checked. However, the valve morphology is so similar, almost identical, to that of the PSW002 material collected at the same location three years earlier that the conspecificity of the animals in the two samples cannot be doubted.

There is a hint of a third lobe occurring ventrally on the ms but, because it is more of a ridge than a lobe we do not interpret it as homologous to full-sized third lobe observed in Trilocypris horwitzi gen. et sp. nov.

Bilocypris mandoraensis gen. et sp. nov.

urn:1sid:zoobank.org:act:41706371-0D1C-486E-91D5-B287EE5C3375

Figs 10-11

\section{Diagnosis}

Valves arched, greatest height situated in middle. RV with anterior and posterior marginal selvage. Marginal tubercles present along anterior, postero-ventral and posterior margins. Lpp with elongated first and second segment; first segment with sub-parallel margins; second segment sickle-shaped and with flagellum-like distal part. Rpp with second segment elongated and somewhat skewed. Hp with lobe 1s boot-shaped, with ventral part sharply pointed, and with distal margin almost straight; lobe ms very broad, more clearly bilobed than in preceding species; distal part of bc short and pointed.

\section{Etymology}

Named after the type locality, Mandora Marsh, Pilbara, Western Australia.

\section{Measurements}

See Table 1.

\section{Type locality}

Fern Spring, Mandora Marsh, Pilbara, West Australia. Coordinates: $19^{\circ} 45^{\prime} 59.9^{\prime \prime}$ S, $121^{\circ} 23^{\prime} 34.1^{\prime \prime}$ E. Collected by Adrian Pinder, 4 Sep. 2015. Nearby Melaleuca Spring (coordinates: 1946'10.7" S, $121^{\circ} 23^{\prime} 21.3^{\prime \prime}$ E) also sampled.

\section{Material examined}

\section{Holotype}

AUSTRALIA • đ; Western Australia, Pilbara, Mandora Marsh, Fern Spring; 1945'59.9" S, $121^{\circ} 23^{\prime} 34.1^{\prime \prime}$ E; 4 Sep. 2015; Adrian Pinder leg.; dissected with soft parts stored in glycerine on a sealed slide and valves stored dry in a micropalaeontological slide; WAM 67226.

\section{Allotype}

AUSTRALIA - O; Western Australia, Pilbara, Mandora Marsh, Melaleuca Spring; 1946'10.7" S, 121 ${ }^{\circ} 23^{\prime 2} 21.3^{\prime \prime}$ E; 4 Sep. 2015; Adrian Pinder leg.; dissected and stored as the holotype; WAM 67601.

\section{Paratypes}

AUSTRALIA • 5 우; same collection data as for allotype; WAM 67227, 67602 to 67605.

\section{Description}

\section{Male}

RV (Fig. 10B, G). Arched, greatest height situated in middle; anterior margin and dorsal margin rounded, posterior margin nearly straight, ventral margin weakly sinuous in middle. With both anterior and posteroventral sub-marginal selvages, anterior and posteroventral margins set with medium-sized 
marginal tubercles. Anterior calcified inner lamella relatively wide, posterior lamella narrow; both lamellae without inners lists.

LV (Fig. 10A). Generally with shape as in RV, slightly larger. Anterior calcified inner lamella slightly wider than in RV, blunt anterior inner list running parallel to most of valve margin, posteriorly with blunt inner list in top part of calcified inner lamella.

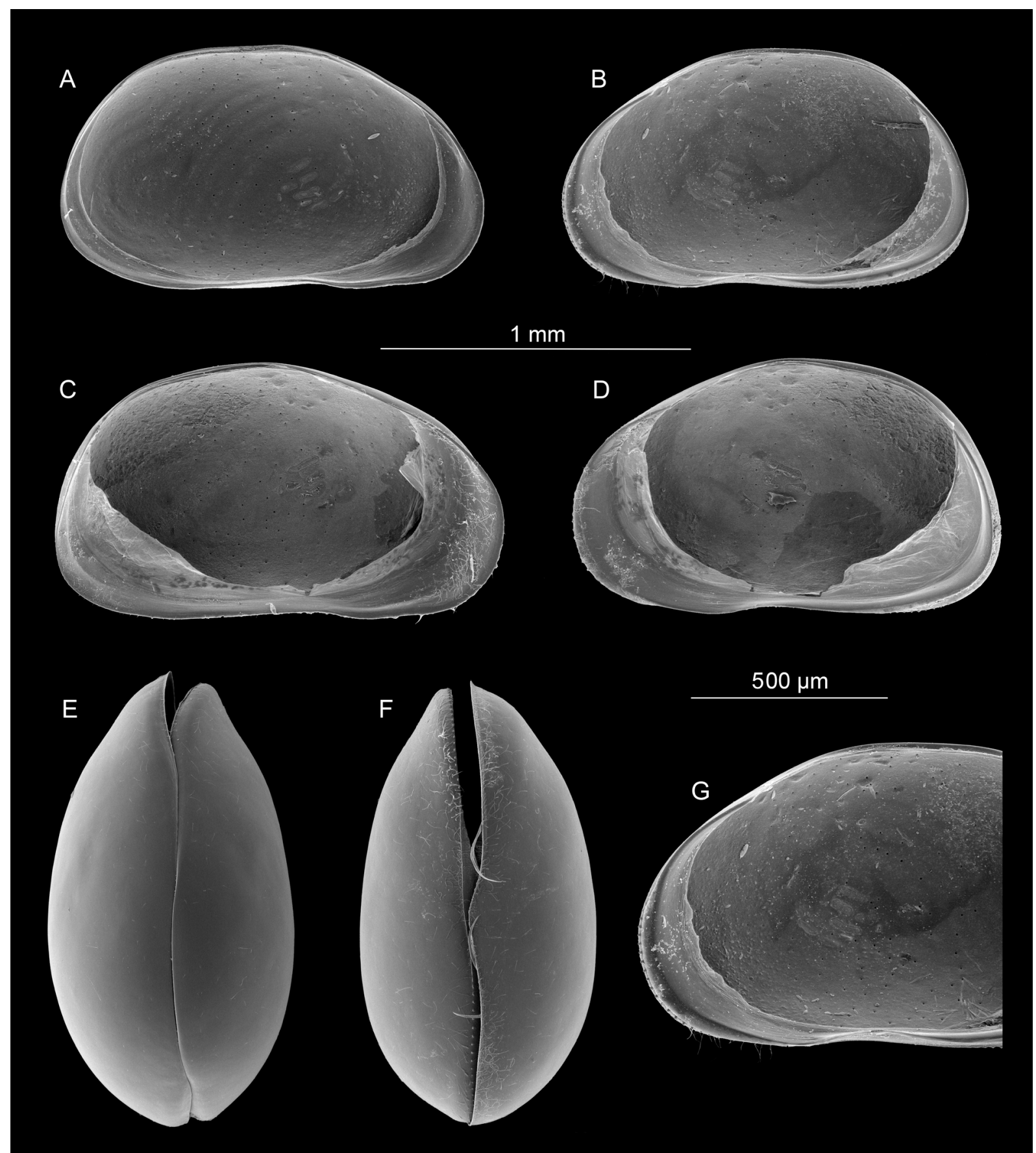

Fig. 10. Bilocypris mandoraensis gen. et sp. nov., Mandora Marsh (type locality). A. LVi, ふ઼, holotype (WAM 67226). B. RVi, Ô, holotype (WAM 67226). C. LVi, + , allotype (WAM 67601). D. RVi, +, allotype (WAM 67601). E. CpD, + , paratype (WAM 67604). F. CpV, +, paratype (WAM 67603). G. RVi, ${ }^{\lambda}$, anterior detail, holotype (WAM 67226). Scales: A-F $=1 \mathrm{~mm} ; \mathrm{G}=500 \mu \mathrm{m}$. 


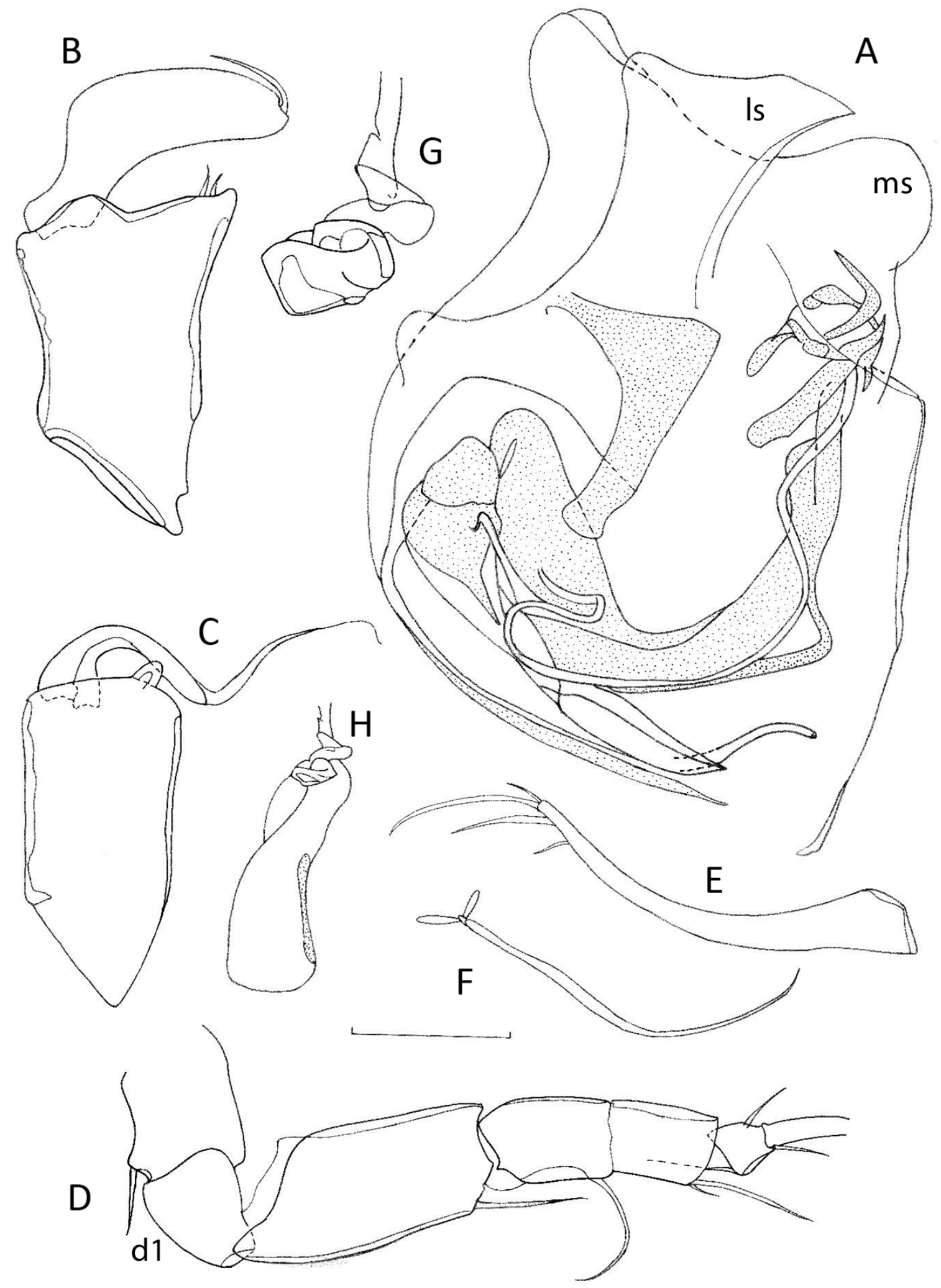

Fig. 11. Bilocypris mandoraensis gen. et sp. nov., Mandora swamp (type locality). A-F. $\overbrace{}^{\Uparrow}$, holotype (WAM 67226). A. Hp. B. Rpp. C. Lpp. D. T2. E. Caudal ramus. F. Support of caudal ramus. G-H. , allotype (WAM 67601). G. Female genital organ. H. Female genital organ, distal detail. Scale: A-D, $\mathrm{H}=92 \mu \mathrm{m} ; \mathrm{E}-\mathrm{F}=232 \mu \mathrm{m} ; \mathrm{G}=37 \mu \mathrm{m}$. 
HALSE S.A. \& MARTENS K., New genera and species of "Heterocypris" from Western Australia

CARAPACE. In dorsal and ventral views with a weak anterior rostrum; greatest width situated in middle. In lateral view with anterior LV/RV overlap most prominent.

Prehensile Palps on T1. Asymmetrical, chaetotaxy of endopodite as typical for family (not shown). Rpp (Fig. 11B) with second segment elongated and somewhat skewed, without additional protrusion on dorso-proximal corner, distal sensory organ medium long. Lpp (Fig. 11C) with nearly rectangular first segment (except for skewed proximal margin) and with ventro-distal expansion broad and rounded; second segment sickle-shaped and narrow, with long and thin distal flagellum-like expansion.

ZENKER ORGAN. As typical of family, i.e., ca 3-5 $\times$ as long as wide and with numerous spinous whorls.

HemiPENIS (Fig. 11A). With 1s shaped as a birdhead, ventrally sharply pointed, with distal margin nearly straight; lobe ms very broad, more clearly bilobed than in preceding species; distal part of bc short and pointed.

Caudal Ramus (Fig. 11E). Curved; its attachment (Fig. 11F) uniramous.

\section{Female}

VALVES (Fig. 10C-D). With shape similar to that of male. Valve margin anatomy as in the male, except for more inwardly displaced posteroventral selvage in LV.

CARAPACE. In dorsal (Fig. 10E) and ventral (Fig. 10F) views with slight anterior rostrum; greatest width situated in middle.

A1, Md, Mx1, T2, T3 and attachment of CR as in male.

A2 (not shown). With distal chaetotaxy showing sexual dimorphism as typical of family.

T1 (not shown). With palp not segmented, relatively elongated.

GenitAL LOBEs. Large and with rounded distal and distally sloping lateral margins (Fig. 11G-H).

\section{Differential diagnosis}

Bilocypris mandoraensis gen. et sp. nov. is closely related to B. fortescuensis gen. et sp. nov. (see above), but can be distinguished from it by its larger size, the more pronounced bilobed nature of the hemipenis lobe ms, the shape of lobe ls (spatulate in B. fortescuensis gen. et sp. nov., pointed boot-shaped in B. mandoraensis gen. et sp. nov.) and the more elongated and skewed shape of the second segment of the Rpp (robust subtriangular in B. fortescuensis gen. et sp. nov.).

\section{Ecology and distribution}

Bilocypris mandoraensis gen. et sp. nov. has been collected from two small, hyposaline, mound springs within Mandora Marsh, which is a very large saline area near the coast of the southern Kimberley region, Western Australia. The marsh is mostly dry, although it has both marine and groundwater influences and occasionally experiences widespread flooding after cyclonic rain (Storey et al. 2011). Bilocypris mandoraensis gen. et sp. nov. was collected at salinities of 7400 and $6280 \mathrm{mg} \mathrm{L}^{-1} \mathrm{TDS}$ in 2015 (Quinlan et al. 2016). The same sites had salinities of 4700 and $5800 \mathrm{mg} \mathrm{L}^{-1}$ in 1999. 


\section{Billcypris gen. nov. urn:1sid:zoobank.org:act:5256267F-1765-435D-A77F-ED6A9C24ECF2}

\section{Type species}

Billcypris davisae gen. et sp. nov. (here designated).

\section{Other species}

The genus is monospecific.

\section{Diagnosis}

Valves higher in posterior half than anterior, LV overlapping RV on all sides. RV with marginal tubercles weakly developed or absent. RV with anterior and posteroventral selvage inwardly displaced. LV anteriorly with blunt inner list, parallel to valve margin. A1 with all segments of normal length/ width ratio. Second segment of Mx1 palp slightly longer than basal width, not curved. Second segment on Lpp without long distal flagellum. Seta $\mathrm{d} 2$ on T2 absent. CR in both male and female less curved and without swollen proximal section; attachment to CR uniramous. Hemipenis with lobe ms pointed and only developed ventrally; lobe ls large and sub-rectangular.

\section{Etymology}

This new genus is named after William 'Bill' Williams (Adelaide, Australia) in honour of the large contributions he has made to Australian limnology, especially in drawing attention to salt lake ecology. Bill was also the PhD supervisor of Patrick De Deckker, after whom the first new genus in this paper was named and, as such, facilitated ostracod research in Australia through Patrick's skills and enthusiasm.

\section{Differential diagnosis}

Billcypris gen. nov. has some valve characteristics that are similar to those in Heterocypris, apart from the absence of strong marginal tubercles on the RV, but differs from all other genera in the Cyprinotinae by the structure of the hemipenis, which consists of a pointed and only ventrally developed lobe ms and a very large and sub-rectangular lobe ls.

The new genus can be distinguished from Cyprinotus by the absence of the dorsal hump on the RV, from Hemicypris and Homocypris by the fact that the LV overlaps the RV (inverse in Hemicypris; valves symmetrical in Homocypris) and from Riocypris by the absence of seta $\mathrm{d} 2$ on limb T2.

\section{Distribution}

The genus is known only from the southern Goldfields region in Western Australia.

\section{Remarks}

As usual in monospecific genera, it is difficult to determine which characters are valid at the generic level and which at the specific level. It is thus possible that the diagnosis of this new genus will have to be adapted if more congeneric species are found.

$$
\begin{aligned}
& \text { Billcypris davisae gen. et sp. nov. } \\
& \text { urn:1sid:zoobank.org:act:3904885C-9677-4739-8B10-5E83D36EB09A }
\end{aligned}
$$

Figs $12-13$

\section{Diagnosis}

Valves highly arched, greatest height situated almost in middle. RV with anterior inwardly displaced selvage, more so in female than in male; marginal tubercles absent or very small and few. LV with 
postero-dorsal extension in male (less developed in females), also visible in carapace in right-lateral view. Lpp with elongated first and second segment, first segment with parallel margins, second segment without long distal flagellum. Hp with very large, sub-rectangular lobe ls and pointed lobe $\mathrm{ms}$, the latter only ventrally developed.

\section{Etymology}

This species is named in honour of Prof. Jenny Davis (Charles Darwin University, Darwin, Australia), in recognition of her significant contributions to Australian limnology, especially of wetlands.

\section{Measurements}

See Table 1.

\section{Type locality}

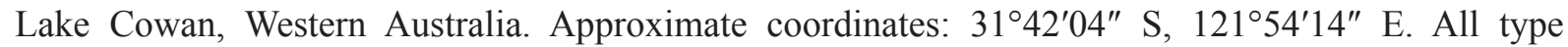
specimens collected by Shane Chaplin, 8 Apr. 1999 (voucher sample no. OSTR064B).

\section{Material examined}

\section{Holotype}

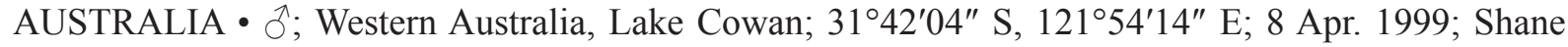
Chaplin leg.; voucher sample no. OSTR064B; with soft parts dissected in glycerine on a sealed slide and with valves stored dry in a micropalaeontological slide; WAM 67217.

\section{Allotype}

AUSTRALIA - o; same collection data as for holotype; dissected and stored as the holotype; WAM 67218.

\section{Paratypes}

AUSTRALIA 11 ; ; same collection data as for holotype; dissected and stored as the holotype; RBINS INV $138038 \cdot 2$ male and 2 female carapaces; same collection data as for holotype; used for SEM and stored dry in a micropalaeontological slide; WAM 67219 to 67222.

\section{Other material}

AUSTRALIA • $1 \mathrm{O}^{\prime}$; Western Australia, Lake Lefroy; $31^{\circ} 17^{\prime} 35^{\prime \prime} \mathrm{S}, 121^{\circ} 41^{\prime} 16^{\prime \prime}$ E [approximate coordinates]; 8 Apr. 1999; Shane Chaplin leg.; dissected and stored as the holotype; WAM $67224 \bullet 6 \widehat{\delta}$, 7 q $\bigcirc$; same collection data as for preceding; in $70 \% \mathrm{EtOH}$ as bulk vouchers; WAM 67225.

\section{Description}

\section{Male}

RV (Fig. 12B-C, K). Arched, greatest height situated in, or just behind, middle; anterior margin rounded, dorsal margin straight and posteriorly sloping over a short distance, posterior margin relatively straight in dorsal section and broadly rounded ventrally, ventral margin almost straight. With both anterior and posteroventral sub-marginal selvage, posterior one somewhat more inwardly displaced than anterior one. Anterior and posteroventral margins with some remnants of marginal tubercles. Calcified inner lamellae narrow, more so posteriorly.

LV (Fig. 12A, J). With a shape generally comparable to that of RV, slightly larger; anterior calcified inner lamella slightly wider than in RV, anteriorly with blunt inner list running parallel to most of valve margin, posteriorly without inner list. Posterodorsal extension of valve present. 
CARAPACE. In dorsal view (Fig. 12F) without anterior rostrum; greatest width situated behind middle. In lateral view (Fig. 12H) with posterodorsal extension on LV prominent.

Prenensile palps on T1. Asymmetrical, chaetotaxy of endopodite as typical for family (not shown). Rpp (Fig. 13B, F) with second segment relatively narrow and curved, distal margin either straight (Fig. 13B) or rounded (Fig. 13F) (possibly depending on position of limb on slide); first segment broad. Lpp (Fig. $13 \mathrm{C}, \mathrm{E})$ with nearly rectangular first segment. Second segment sickle- shaped and narrow, of variable length, and without distal flagellum-like expansion.

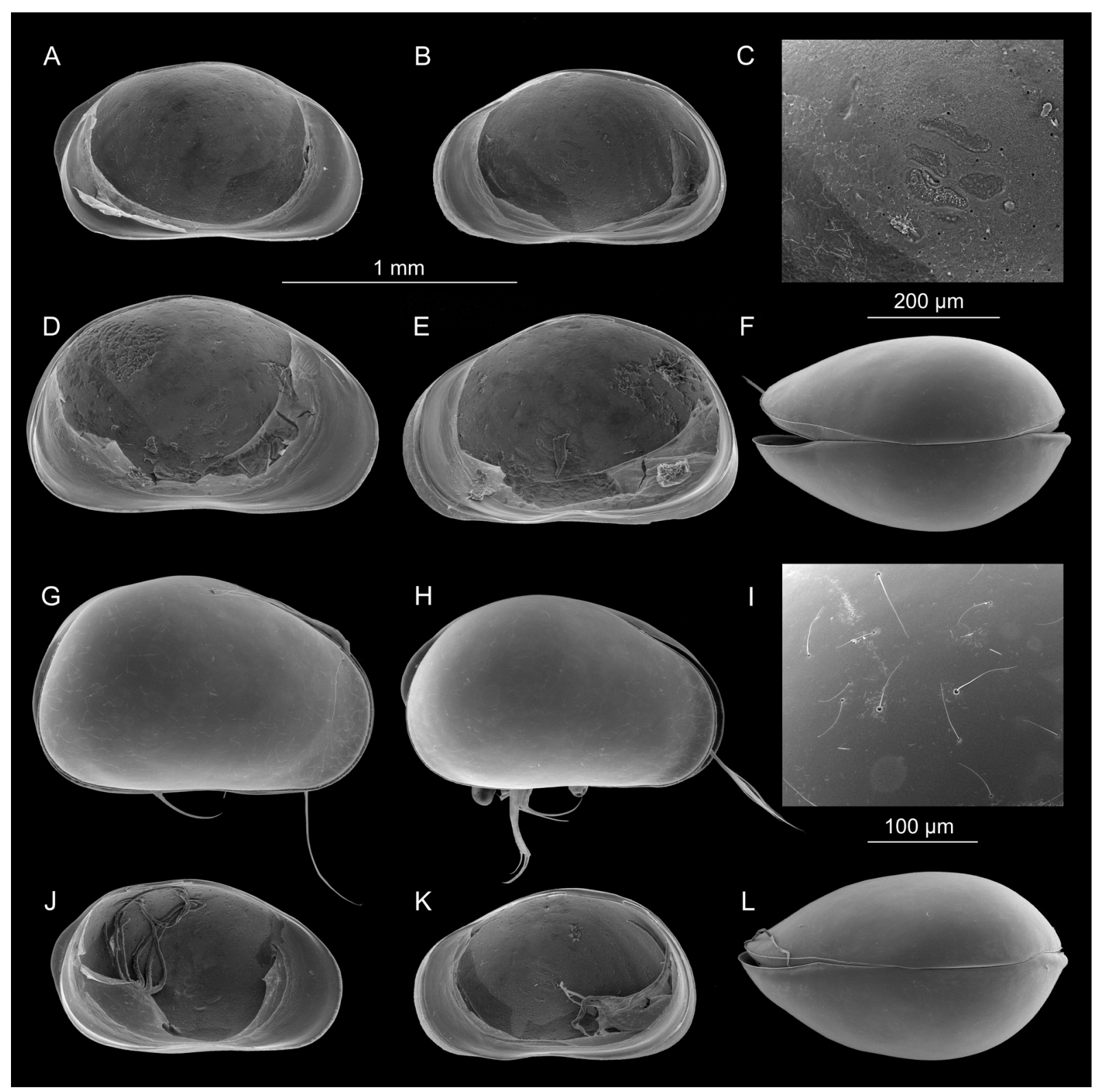

Fig. 12. Billcypris davisae gen. et sp. nov. A-I, L. Lake Cowan (type locality, sample OSTR064B). J, K. Lake Lefroy (sample OSTR063A). A. LVi, ô, holotype (WAM 67217). B. RVi, ð̃, holotype (WAM 67217). C. RVi, detail of central muscle scars, ô, holotype (WAM 67217). D. LVi, $q$, allotype (WAM 67218). E. RVi,, , allotype (WAM 67218). F. CpD, ô (WAM 67222). G. CpRL, $ᄋ$ (WAM 67219). H. CpRL, ô (WAM 67221). I. CpRL, detail of external surface, $q$ (WAM 67219). J. LVi, ô (WAM 67224). K. RVi, ô (WAM 67224). L. CpD, $q$ (WAM 67220). Scales: A-B, D-H, J-L = $1 \mathrm{~mm} ; \mathrm{C}=200 \mu \mathrm{m}$; I = $100 \mu \mathrm{m}$. 


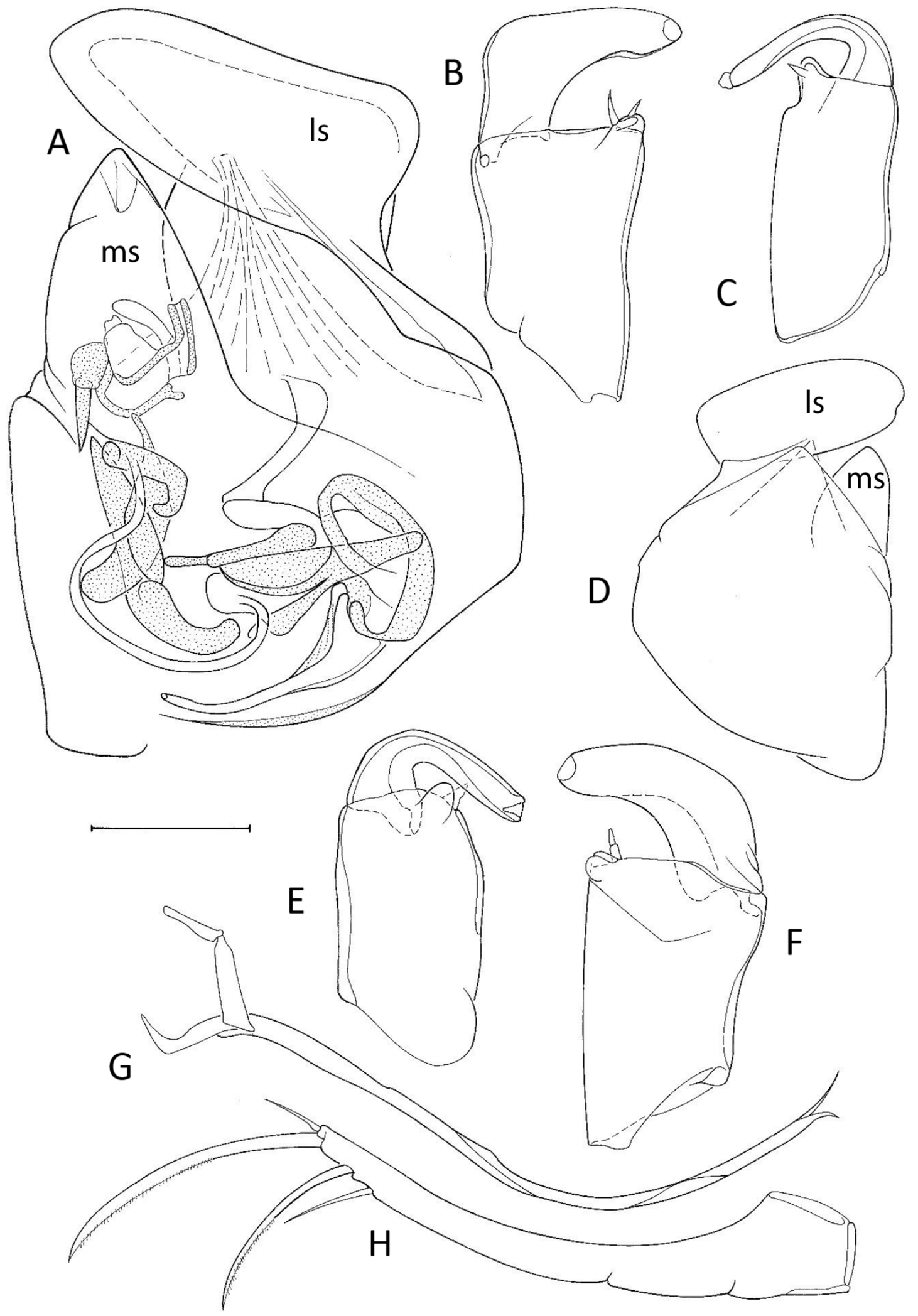

Fig. 13. Billcypris davisae gen. et sp. nov., Lake Cowan (type locality, sample OSTR064B). A-C. ठ̊̄, holotype (WAM 67217). A. Hp. B. Rpp. C. Lpp. D-F. O’, paratype (RBINS INV 138038). D. Hp outline. E. Lpp. F. Rpp. G-H. O, holotype (WAM 67217). G. CR attachment (note: the bifurcation at the left side is the basis of the actual CR). H. CR. Scale: A-C, $\mathrm{E}-\mathrm{H}=92 \mu \mathrm{m} ; \mathrm{D}=232 \mu \mathrm{m}$. 
ZENKER ORGAN. As typical of family, i.e., ca 3-5 $\times$ as long as wide and with numerous spinous whorls.

HemiPenis (Fig. 13A, D). With lobe ls large and sub-rectangular, with blunt point extending ventrally beyond edge of hemipenis; ms triangular and bluntly pointed.

CAUDAl Ramus (Fig. 13H). Curved and proximally hardly expanded; its attachment (Fig. 13G) uniramous (note: the bifurcation on the left side on Fig. 13G is actually the proximal part of the CR itself).

\section{Female}

VALVES (Fig. 12 D-E). With shape similar to those of male, but with posteroventral extension on LV much smaller and even absent in some specimens. Valve margin anatomy as in male, except for selvage in RV being more inwardly displaced, both anteriorly and posteriorly.

CARAPACE. In dorsal view (Fig. 12L) as in male. In lateral view (Fig. 12G, I) with posteroventral lump of LV still visible in some specimens, absent in others.

$\mathrm{A} 1, \mathrm{Md}, \mathrm{Mx} 1, \mathrm{~T} 2, \mathrm{~T} 3$ and attachment of $\mathrm{CR}$ as in male.

A2 (not shown). With distal chaetotaxy showing sexual dimorphism as typical of family.

T1 (not shown). With palp not segmented, relatively short and broad.

\section{Differential diagnosis}

This species can at once be distinguished from all others in the subfamily Cyprinotinae by the very large lobe ls and the pointed lobe ms on the hemipenis. The posterodorsal extension on the LV, especially in the male, is also characteristic, but similar features have been seen in other, as yet undescribed, species of West Australian Heterocypris.

\section{Ecology and distribution}

Billcypris davisae gen. et sp. nov. appears to be a halophilic species, collected from Lakes Cowan and Lefroy near Norseman, Western Australia. Both are shallow hypersaline playas that are typically dry but may be shallowly inundated for a few months in wet years. Both lakes are surrounded by smaller playas that are inundated by smaller rainfall events and tend to be less saline. No information on salinities at the time of collecting is available.

\section{Discussion}

\section{Heterocypris as a polyphyletic genus}

The genus Heterocypris currently contains 62 subjective species from all zoogeographical realms of the globe (except Antarctica) and there are an additional 38 species names that are synonyms of the subjective species (Meisch et al. 2019). These 100 nominal species mostly (but not always) share three simple sets of characters, namely that they are cypridids in which the LV overlaps the RV and the RV is set with marginal tubercles, at least along the anterior and postero-ventral margin. Other than that, few uniting characters have been considered when describing new species of Heterocypris. Some discussion of valve characters is warranted in view of the four new genera described here and may help in a future, world-wide revision of the genus Heterocypris.

It seems plausible that Heterocypris will have to be subdivided into several genera to reflect the occurrence of separate natural and monophyletic lineages. The incomplete description of many existing Heterocypris species will hamper such a revision and type materials will have to be consulted whenever 
possible. Molecular analysis of fresh topotype material will undoubtedly also prove to be highly valuable, because integrative taxonomy is usually essential when resolving polyphyletic taxa.

The following discussion refers to the morphology of the type species, Heterocypris incongruens (Ramdohr, 1808), and focuses on the arguments for differentiating the four new genera from Heterocypris s. str.

\section{Morphology of the valve margins}

The presence or absence of selvages or inner lists in both valves, and even the degree of inward displacement of the selvages, have proven to be valid characters to distinguish natural lineages at the genus level within the Cyprididae. They have been used to separate genera within, for example, the Megalocypridinae (Martens 1986) and the Cypridinae (Martens 1990, 1992), and also to keep seemingly different species together in one genus, as in Herpetocypris (Gonzalez Mozo et al. 1996) and in the Australian genus Bennelongia (Martens et al. 2012, 2013, 2015). Past descriptions of new species in the genus Heterocypris have often ignored these characters despite their obvious importance in the case of fossil taxa, for which there are few other characters that can be used to assign species to genera.

Heterocypris incongruens, which defines Heterocypris s. str., has a sub-marginal anterior selvage and no inner list in the RV. The LV has neither selvage, nor inner lists.

Of the four new genera described here, Trilocpris gen. nov., Bilocypris gen. nov. and Billcypris gen. nov. conform to the body plan of Heterocypris s. str. in relation to marginal valve morphology. Patcypris gen. nov. is clearly different from Heterocypris s. str. in that it lacks anterior selvages and inner lists in both valves. Of the better described species assigned to the genus Heterocypris, at least Heterocypris margaritae Margalef, 1961 (re-description in Broodbakker 1982) also seems to lack inner lists and selvages in both valves, which would therefore also exclude it from the genus Heterocypris s. str. However, the layout of the hemipenis of this species is typical of Heterocypris s. str. (see below) and therefore it cannot be assigned to Patcypris gen. nov.

The valve outline of the five new species here described is remarkably similar. Yet, details of the morphology of the valve margins and certainly of the hemipenis and the prehensile palps are so different that the four new genera most likely do not belong to the same monophyletic lineage, and the similar valve shapes of all five species are the result of convergent evolution. DNA sequencing of these and other Australian species of 'Heterocypris' should be used to confirm this when material becomes available.

\section{Setae d1 and d2 on T2}

The presence/absence and the length ratio of the $\mathrm{d} 1$ and $\mathrm{d} 2$ setae has been used to delimit genera and tribes within subfamilies of Cyprididae, such as the genera of the Eucypridinae (Martens 1989) and tribes of the Herpetocypridinae (Martens 2001) and Cypricercinae (Savatenalinton \& Martens 2009).

It appears that all genera within the Cyprinotinae have a short seta $\mathrm{d} 1$ and no seta $\mathrm{d} 2$, except for the genus Riocypris, where both setae are present but seta $\mathrm{d} 1$ is much longer than seta $\mathrm{d} 2$. However, the status of the $\mathrm{d} 1$ and $\mathrm{d} 2$ setae is unknown for a large number of species of Heterocypris because they were not included in the original descriptions. Moreover, the absence of the setae is potentially an unreliable character, as the basal segments of T2 are often lost during dissection or the setae may have been lost or be difficult to see. For several specimens used during the present research, the presence of seta $\mathrm{d} 1$ could not be established, but for at least some specimens of each of the new species described here the d1 seta was seen. The $\mathrm{d} 2$ seta was always absent. 


\section{Attachment of the caudal ramus}

Triebel (1953) was the first to show the relevance of the morphology of the attachment of the caudal ramus ("furca") to higher taxonomy in Podocopida in general and in Cyprididae in particular. De Deckker (1979) confirmed the validity of this character while Rome (1969) had shown that the so-called "Triebel's loop" is a unique character uniting all species and genera within the Cypricercinae (see also Savatenalinton \& Martens 2009). Within Heterocypris s. lat., three different types of attachment have thus far been illustrated: a normal distally bifurcated attachment (Rome 1969), a ramus with a more centrally situated side branch (e.g., H. vatia in De Deckker 1981a; H. makua in Victor \& Fernando 1980, 1981; also H. incongruens in Okubo 1972) and a uniramous morphology as found in H. antillenis (Broodbakker, 1982) and the present five species and four genera. Karanovic (2012) illustrated both a ramus with a central side branch and a uniramous morphology for one and the same species of Cyprinotus, suggesting that potential incidences of asymmetry in this character must be taken into account.

\section{Structure of the hemipenis}

The shape of the hemipenis is usually considered to be quite plastic within a genus, because this is a feature on which sexual selection can act strongly; hence large differences between species in the same genus might be expected and ostracod taxonomists mostly use this character to distinguish between congeneric species. This is certainly the case in, for example, the genera Sclerocypris (see Martens 1986) and Diacypris (see De Deckker 1981b).

However, in other genera the basic body plan of the hemipenis often remains unchanged among species within the same genus. This is the case for most species of Heterocypris s. str. in which males are known. The basic body plan of the Heterocypris hemipenis comprises a bluntly rounded medial shield (ms), produced towards the ventral side, and a longer lateral shield (1s) that is boot-shaped with a ventrally directed point (or toe). In fact, this basic body plan of the hemipenis applies to species in all genera thus far known in the Cyprinotinae. The hemipenes in the five new species in the four new genera described here deviate significantly from this basic body plan.

\section{Conclusions}

When significant deviations from the basic body plan occur, they may have relevance at a higher taxonomic level than that of the species. Here, we have recognised four significantly different plans of hemipenis structure and have translated these into four new genera within the Cyprinotinae.

1. Patcypris gen. nov.: lobe 1s hyperdeveloped into a pickaxe-shaped lobe, lobe ms bilobed. This hemipenis morphology is matched with the absence of anterior selvages and inner lists on both valves, giving the genus significantly different hemipenis and valve plans from those of Heterocypris.

2. Trilocypris gen. nov.: three (instead of two) lobes of equal length are present, with the boot-shaped lobe ls occurring between the other two lobes. It is assumed that the lobe os is the newly formed lobe.

3. Bilocypris gen. nov.: lobe ms is very wide and weakly to clearly indented in the middle, while lobe 1s is weakly developed, being either a short boot-shape or spatulate in the species described here.

4. Billcypris gen. nov.: lobe $\mathrm{ms}$ is reduced to an elongated ventral lobe, while lobe ls is hyperdeveloped into a very large sub-rectangular lobe.

We recognise that describing a series of monospecific genera is somewhat awkward; however, the discovery of two species of the genus Bilocypris gen. nov. suggests that additional sampling in other lakes of the arid zone of Western Australia may show that multiple species do occur within these genera. The occurrence of additional species would support our use of the structure of the hemipenis to define supra-specific taxa in this subfamily. Support for the notion that additional species will be found is 
HALSE S.A. \& MARTENS K., New genera and species of "Heterocypris" from Western Australia

provided by the sampling of many seasonally or, more commonly episodically, flooded wetlands in Western Australia. This sampling, from only a small proportion of the myriad of wetlands present, has regularly found new species of ostracods, including many Heterocypris-like species (Halse 2002; Halse et al. 2004; Pinder et al. 2010). Perhaps the most compelling evidence for the existence of additional species in almost every genus is the dramatic increase in the number of described Western Australian species of Bennelongia (from 2 to 24, with other undescribed species known) that resulted from the sampling and taxonomic work of Martens et al. (2012, 2013, 2015).

\section{Acknowledgements}

The authors gratefully acknowledge the financial support of an ABRS-grant (nr RF211-33: 'Biodiversity and taxonomy of Ostracoda (Crustacea) from temporary water bodies of inland Western Australia') and of the Edith Cowan University Industry Collaboration grant. KM acknowledges the Western Australian Department of Biodiversity, Conservation and Attractions (2006) and Bennelongia Pty Ltd (2008, 2009, 2010) for financial support during several scientific stays in Perth, as well as the financial contribution of the FWO Vlaanderen (Fund for Scientific Research, Flanders) in the form of travel grants in 2010 (V4.172.10N and V4.173.10N) and the projects 1.5.172.09 (krediet aan navorsers) and G.0118.03N (projectonderzoek). KM also thanks the people of Bennelongia Pty Ltd (Perth, WA) for continuous logistic support (lab space, use of microscopes) and for unfailing companionship in the lab. KM also deeply thanks his partner Isa Schön and their son Emrys for help during previous stays in Perth. Julien Cilis, Claudine Behen and Charlotte Gérard, (RBINS, Brussels, Belgium) provided technical assistance with the SEM micrographs and with the line drawings. Anton Mittra and Jane McRae (Bennelongia Pty Ltd, Perth, WA) produced the map in Fig. 1 and rearranged the micrographs and line drawings. Several colleagues who collected the material used here are thanked in the course of the species descriptions. Two anonymous referees provided helpful comments on the manuscript.

\section{References}

Broodbakker N.W. 1982. The genus Heterocypris (Crustacea, Ostracoda) in the West Indies. Part I. Taxonomic characters. Bijdragen tot de Dierkunde 52: 207-227.

De Deckker P. 1979. Evaluation of features distinctive in the taxonomy of the Cypridacea, above the generic level. In: Krstić N. (ed.) Proceedings of the VII International Symposium on Ostracodes: 9-17. Serbian Geological Society, Belgrade.

De Deckker P. 1981a. Ostracoda from Australian inland waters - notes on taxonomy and ecology. Proceedings of the Royal Society of Victoria 93: 43-85.

De Deckker P. 1981b. Taxonomic notes on some Australian ostracods with descriptions of new species. Zoologica Scripta 10: 37-55. https://doi.org/10.1111/j.1463-6409.1981.tb00483.x

Gonzalez Mozo M., Martens K. \& Baltanas A. 1996. A taxonomic revision of European Herpetocypris Brady \& Norman, 1889 (Crustacea, Ostracoda). Bulletin van het Koninklijk Belgisch Instituut voor Natuurwetenschappen, Biologie 66: 93-132.

Halse S.A. 2002. Diversity of Ostracoda (Crustacea) in inland waters of Western Australia. Verhandlungen der Internationale Vereinigung für theoretische und angewandte Limnologie 28: 914-918.

Halse S.A. \& McRae J.M. 2004. New genera and species of giant ostracods (Crustacea: Cyprididae) from Australia. Hydrobiologia 524: 1-52. https://doi.org/10.1023/b:hydr.0000036197.03776.46

Karanovic I. 2008. Three interesting Cyprididae (Ostracoda) from Western Australia. Records of the Western Australian Museum 24: 267-287. https://doi.org/10.18195/issn.0312-3162.24(3).2008.267-287

Karanovic I. 2012. Recent Freshwater Ostracods from the World. Springer, Heidelberg. https://doi.org/10.1007/978-3-642-21810-1 
Martens K. 1986. Taxonomic revision of the subfamily Megalocypridinae Rome, 1965 (Crustacea, Ostracoda). Verhandelingen van de koninklijke Academie voor Wetenschappen, Letteren en Schone Kunsten, Klasse der Wetenschappen 48 (174): 1-81.

Martens K. 1989. On the systematic position of the Eucypris clavata-group, with a description of Trajancypris gen. nov. (Crustacea, Ostracoda). Archiv für Hydrobiologie, Supplement 83 (2): 227-251.

Martens K. 1990. Taxonomic revision of African Cypridini. Part I. The genera Cypris O.F. Müller, Pseudocypris Daday and Globocypris Klie. Bulletin van het Koninklijk Belgisch Instituut voor Natuurwetenschappen, Biologie 60: 127-172.

Martens K. 1992. Taxonomic revision of African Cypridini. Part II. Description of Ramotha gen. nov. Annals of the South African Museum 102 (2): 91-130.

Available from https://biodiversitylibrary.org/page/40750709 [accessed 11 Dec. 2018].

Martens K. 2001. Taxonomy of the Herpetocypridinae (Crustacea, Ostracoda). Crustaceana 74: 295-308. https://doi.org/10.1163/156854001505532

Martens K. \& Higuti J. (in press). Chapter 21, Class Ostracoda. In: Thorpe \& Covich's Freshwater Invertebrates. Elsevier, San Diego.

Martens K., Schön I., Meisch C. \& Horne D.J. 2008. Global biodiversity of non-marine Ostracoda (Crustacea). Hydrobiologia 595: 185-193. https://doi.org/10.1007/s10750-007-9245-4

Martens K., Halse S. \& Schön I. 2012. Nine new species of Bennelongia De Deckker \& McKenzie, 1981 (Crustacea, Ostracoda) from Western Australia, with the description of a new subfamily. European Journal of Taxonomy 8: 1-56. https://doi.org/10.5852/ejt.2012.8

Martens K., Halse S. \& Schön I. 2013. On the Bennelongia barangaroo lineage (Crustacea, Ostracoda) in Western Australia, with the description of seven new species. European Journal of Taxonomy 66: 1-59. https://doi.org/10.5852/ejt.2013.66

Martens K., Halse S. \& Schön I. 2015. On the Bennelongia nimala and B. triangulata lineages (Crustacea, Ostracoda) in Western Australia, with the description of six new species. European Journal of Taxonomy 111: 1-36. https://doi.org/10.5852/ejt.2015.111

Meisch C., Smith R. \& Martens K. 2019. A subjective global checklist of the Recent non-marine Ostracoda (Crustacea). European Journal of Taxonomy 492: 1-135. https://doi.org/10.5852/ejt.2019.492

Okubo I. 1972. Freshwater Ostracoda from Japan, IV. Heterocypris incongruens (Ramdohr, 1808). Review of the Shujitsu Junior College, Okayama 1: 73-84.

Pinder A.M, Halse S.A., Shiel R.J. \& McRae J.M. 2010. An arid zone awash with diversity: patterns in the distribution of aquatic invertebrates in the Pilbara region of Western Australia. Records of the Western Australian Museum, Supplement 78: 205-246.

https://doi.org/10.18195/issn.0313-122x.78(1).2010.205-246

Quinlan K., Pinder A. \& Lewis L. 2016. Aquatic Fauna Survey at Mandora Marsh (Walyarta) in September 2015. Department of Parks and Wildlife, Kensington, Western Australia, Australia.

Rome D.R. 1969. Morphologie de l'attache de la furca chez les Cyprididae et son utilisation en systématique. In: Neale J. (ed.) The Taxonomy, Morphology and Ecology of Recent Ostracoda: 168193. Olivier \& Boyd, Edinburgh.

Savatenalinton S. \& Martens K. 2009. Generic revision of Cypricercinae McKenzie, 1971 (Crustacea, Ostracoda), with the description of three new genera and one new species and a phylogenetic analysis of the subfamily. Hydrobiologia 632: 1-48. https://doi.org/10.1007/s10750-009-9826-5 
Shearn R., Koenders A., Halse S., Schön I. \& Martens K. 2012. A review of Bennelongia De Deckker \& Mckenzie, 1981 (Crustacea, Ostracoda) species from eastern Australia, with the description of three new species. European Journal of Taxonomy 25:1-35. https://doi.org/10.5852/ejt.2012.25

Storey A.W., Halse S.A., Shiel R.J. \& Creagh S. 2011. Aquatic fauna and water chemistry of the mound springs and wetlands of Mandora Marsh, north-western Australia. Journal of the Royal Society of Western Australia 94: 419-437.

Triebel E. 1953. Genotypus und Schalen-Merkmale der Ostracoden Gattung Stenocypris. Senckenbergiana 34: 5-14.

Victor R. \& Fernando C.H. 1980. On Heterocypris makua (Tressler, 1937), a freshwater ostracod (Crustacea, Ostracoda) from the Hawaiian Islands, with notes on other species of the genus. Canadian Journal of Zoology 58 (7): 1288-1297. https://doi.org/10.1139/z80-180

Victor R. \& Fernando C.H. 1981. Freshwater ostracods (Crustacea, Ostracoda) of the subfamily Cyprinotinae Bronstein, 1947 from Malaysia, Indonesia and the Philippines. Hydrobiologia 83: 11-27. https://doi.org/10.1007/bf02187148

Manuscript received: 4 September 2018

Manuscript accepted: 16 November 2018

Published on: 29 January 2019

Topic editors: Rudy Jocqué

Desk editor: Danny Eibye-Jacobsen

Printed versions of all papers are also deposited in the libraries of the institutes that are members of the EJT consortium: Muséum national d'Histoire naturelle, Paris, France; Meise Botanic Garden, Belgium; Royal Museum for Central Africa, Tervuren, Belgium; Natural History Museum, London, United Kingdom; Royal Belgian Institute of Natural Sciences, Brussels, Belgium; Natural History Museum of Denmark, Copenhagen, Denmark; Naturalis Biodiversity Center, Leiden, the Netherlands; Museo Nacional de Ciencias Naturales-CSIC, Madrid, Spain; Real Jardín Botánico de Madrid CSIC, Spain; Zoological Research Museum Alexander Koenig, Bonn, Germany. 